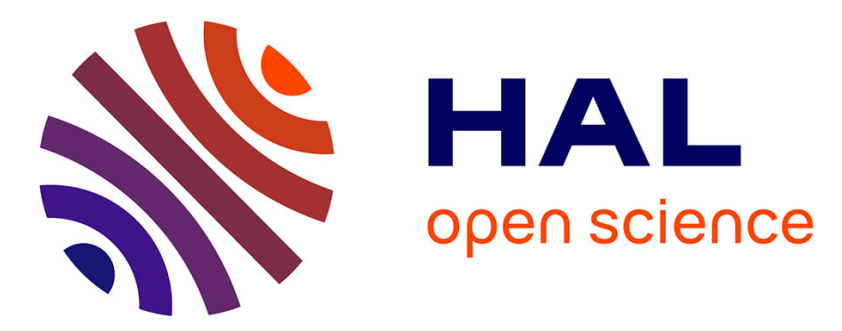

\title{
Characterization and micromechanical modelling of microstructural heterogeneity effects on ductile fracture of $6 \times x x$ aluminium alloys
}

F Hannard, T Pardoen, Éric Maire, Christophe Le Bourlot, R Mokso, A Simar

\section{- To cite this version:}

F Hannard, T Pardoen, Éric Maire, Christophe Le Bourlot, R Mokso, et al.. Characterization and micromechanical modelling of microstructural heterogeneity effects on ductile fracture of $6 \mathrm{xxx}$ aluminium alloys. Acta Materialia, 2016, 103, pp.558-572. 10.1016/j.actamat.2015.10.008 . hal-01523721

\section{HAL Id: hal-01523721 \\ https://hal.science/hal-01523721}

Submitted on 24 May 2017

HAL is a multi-disciplinary open access archive for the deposit and dissemination of scientific research documents, whether they are published or not. The documents may come from teaching and research institutions in France or abroad, or from public or private research centers.
L'archive ouverte pluridisciplinaire HAL, est destinée au dépôt et à la diffusion de documents scientifiques de niveau recherche, publiés ou non, émanant des établissements d'enseignement et de recherche français ou étrangers, des laboratoires publics ou privés. 


\title{
Characterization and micromechanical modelling of microstructural heterogeneity effects on ductile fracture of 6xxx aluminium alloys
}

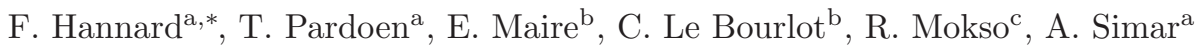 \\ ${ }^{a}$ Institute of Mechanics, Materials and Civil Engineering, Université catholique de Louvain, B-1348 Louvain-la-Neuve, \\ Belgium \\ ${ }^{b}$ MATEIS UMR5510, INSA-Lyon, F-69621 Villeurbanne, France \\ ${ }^{c}$ Swiss Light Source, Paul Scherrer Institute, Villigen, 5232, Switzerland
}

\begin{abstract}
Ductile failure of three 6xxx serie aluminium alloys has been characterized and modelled for about thirty hardening conditions each. These alloys involve relatively similar composition and volume fraction of second phase particles. The tensile mechanical properties show the expected decrease of fracture strain with increasing strength but also major differences among the different alloys with a factor ten in terms of reduction of area at fracture between best and worst case. The origin of these differences is unraveled by detailed characterization of the void nucleation, growth and coalescence process involving in situ 3D microtomography. A cellular automaton model, involving a high number of particles with distributions of position, sizes and void nucleation stress is developed to predict the fracture strain. Excellent predictions are obtained based on the same unique nucleation stress distribution versus particle size for the three alloys. The key element setting the fracture strain is the effect of particle size distribution and spatial distribution on the void nucleation and coalescence processes. The dependence of ductility on strength is properly captured as well.

Keywords: damage initiation, aluminium alloys, X-ray tomography, Intermetallics, Cellular automaton model
\end{abstract}

\section{Introduction}

Ductile fracture results from the nucleation, growth and coalescence of small internal cavities. Microvoid nucleation is usually associated with the fracture of brittle particles or interface decohesion $[1,2]$. After nucleation, voids grow by plastic deformation of the surrounding matrix [3]. During the last four decades, ductile fracture has been a subject of intense investigation in the solid mechanics and material science communities [3]. The first micromechanical treatments due to McClintock [4] and Rice and Tracey [5] considered isolated voids. Stable growth proceeds until plasticity localizes within the ligament between closely spaced cavities setting the onset of the coalescence mechanism [6]. The accumulation of void linkages leads to the formation of a dominant macroscopic crack that finally propagates into the entire material. The understanding and modelling of the different steps of the process of nucleation, growth, and coalescence

\footnotetext{
${ }^{*}$ Corresponding author. florent.hannard@uclouvain.be, Tel.: +32.10.47.24.39, fax: +32.10.47.40.28
} 
of voids have been enhanced over the years, as covered in several recent review papers $[3,7,8]$. However, major questions remain about the understanding and proper modelling of ductile fracture in metals involving significant microstructure heterogeneities. This introduction proceeds with a review of the main issues related to heterogeneities and how they affect damage evolution and complexify the application of existing models.

Void nucleation is inherently a discontinuous process made of a succession of discrete nucleation events [7]. The effect of particle size, associated with the distribution of internal or interfacial defects, can be a dominant feature of the inhomogeneity of the damage process. Void nucleation becomes increasingly difficult with decreasing particle size since the largest defects are more likely to be found in the largest inclusions. The particle shape combined to the loading orientation can also contribute to the heterogeneity of the nucleation process $[9,10]$. Furthermore, the interfacial resistance between second phase particles and surrounding matrix is dependent on the local chemical composition [7]. Nucleation can be inhomogeneous also because the load transfer in the particles depends on local microplasticity effects related to microstructure details and local crystallography, see e.g. [11]. Heterogeneities in the spatial distribution of the second phases which can be spatially clustered lead to local stress concentrations [12]. All these effects could in principle be rationalized using micromechanics based nucleation criteria. The Beremin group proposed a void nucleation model valid for a range of particle sizes formulated within a continuum approach [9], based on a critical value of maximum principal stress in the particle or at the interface. The model accounts for plastic strain incompatibility between the matrix and inclusion and for particle shape. The effects of inclusion orientation and of complex loading path on nucleation have been addressed by finite element(FE) simulations on complex multiparticle cells [13].

Voids nucleated by particle fracture are initially flat and become more rounded with plastic deformation. Voids nucleated by interface decohesion are initially rounded and tend to elongate in the principal loading direction under low stress triaxiality. Heterogeneities in the void distribution do not significantly affect the void growth rates $[14,15,16,17]$ and the interaction between voids during the growth phase is usually weak in industrial alloys (i.e. with low volume fraction of constituent particles). However, these interactions become significant in void clusters of highly heterogenous materials (e.g.,[18]). For instance, small voids in the neighborhood of large cavities grow much faster than in a single size population [19, 20]. The void growth rate depends also on the local crystallographic orientation [21]. Aside from the simple analytical models for isolated voids, constitutive models for porous plastic materials were developed based on homogenization theory but without interaction effects, see in particular the Gurson model [22] and a realm of its extensions $[23,17,24,25,26,27,28,29,10,30,31]$.

The dominant parameter controlling the transition from stable growth to coalescence is the relative void spacing which can be highly heterogeneous if particles are clustered. If coalescence proceeds after significant amount of void growth, the failure is said "void controlled". When nucleation is rapidly followed by void coalescence with limited amount of void growth, the fracture mechanism is said to be "nucleation controlled" such as observed for instance in high strength $\mathrm{Al}$ alloys [32]. Significant progress has been made over the 
past two decades in the micromechanical modeling of coalescence, mainly along the lines of the approach developed by Thomason [6] with several generalizations [17, 20, 33, 34, 35, 36, 37, 38]. The proximity within clusters of voids, see e.g. [16], has a huge effect on coalescence because the dominant parameter is the relative void spacing.

The impact of heterogeneities on damage accumulation until cracking can be modelled in many different ways, see review [8]. One approach consists in averaging the response on large RVE through statistical treatment of void nucleation. This statistical treatment can be connected to the Beremin model [9] based on a weakest link approach through a Weibull distribution for particle fracture stress [39] or based on more simple distributions, see [40,41]. A mean average porosity is assumed for the void growth phase and coalescence is treated by accounting for a nearest neighbours void spacing [42]. More advanced approaches consist in representing the microstructure and property heterogeneities in a systematic way. For instance, damage percolation models have been developed to capture cluster effects on coalescence and cracking [32, 43]. Heterogeneous damage nucleation can also be taken into account in FE calculations with different void nucleation rates in each element [44]. Probably the most sophisticated approach is to generate a large ensemble of particles, following physical distribution, and to simulate all steps of the damage process without the need for approximate nucleation, growth and coalescence laws [45].

From an experimental view point, 3D X-ray tomography is perfectly suited to study the effect of microstructure heterogeneity on all steps of ductile failure. It allows non-destructive local characterization of the microstructure and quantitative analysis of the morphology of the particles associated to void nucleation [39]. The results of in situ tensile tests in X-ray tomography have lead to a quantitative characterization of the initiation [46], growth [47] and coalescence [48] in high strength steels, $\mathrm{Al}$ and Ti alloys.

The goal of the present study is to understand and model the effect of microstructure heterogeneities on damage accumulation in three $6 \mathrm{xxx}$ series $\mathrm{Al}$ alloys, but with a methodology that can be directly extended to any other metallic alloy. These alloys, i.e. $\mathrm{Al} 6005 \mathrm{~A}, \mathrm{Al} 6061$ and $\mathrm{Al} 6056$, exhibit a volume fraction of iron rich particles close to $1 \%$. However, the variation of fracture strain as a function of yield stress shown in Fig. 1.a (and explained further in this paper) is very different, involving a factor 10 in the reduction of area between the extreme cases (i.e. factor 3 in true "log" fracture strain). In a preliminary study [49], a recent advanced extension of Gurson's model for porous ductile metals has been applied in order to reproduce this effect. However, because of the very small difference in volume fraction of Fe based particles, the model was not rich enough to allow capturing the differences between the three alloys. This negative outcome motivated the formulation of a physical model which does not rely on an average description of the microstructure. Furthermore, damage models are rarely challenged in applications involving wide datasets encompassing several materials and heat treatments. This is the purpose of the paper to describe the key experimental results regarding damage evolution motivating the need for a model that accounts for microstructural heterogeneities.

The outline of the paper is the following. Section 2 introduces the experimental methods used for the 
microstructural and mechanical characterization of the three alloys. The damage model is described in section 3. Subsequently, section 4 starts with the experimental results which are used for the identification of the damage model. The model is then validated by comparison with additional experimental data.

\section{Experimental methods}

\subsection{Materials}

The fracture of $6005 \mathrm{~A}, 6061$ and $6056 \mathrm{Al}$ alloy, is investigated under a wide range of heat treatment conditions in order to allow cross-comparisons at identical yield strength. Table 1 presents the chemical composition as measured by inductively coupled plasma optical emission spectroscopy. The alloys are provided in extruded plates (6005A alloy) or cold rolled plates (6061 and 6056 alloys), the rolling or extrusion directions are refered as the "primary" processing direction. The thickness of the plates is equal to $6 \mathrm{~mm}$ for the $6005 \mathrm{~A}$ and 6056 alloys and $4.7 \mathrm{~mm}$ for the 6061 alloy.

The alloys are initially in T4 (6056 alloy) or T6 conditions (6005A and 6061 alloys). Some plates provided in $\mathrm{T} 6$ condition are transformed into $\mathrm{T} 4$ condition by a solution heat treatment of 1 hour at $535 \mathrm{C}$ for the 6061 alloy and at $530 \mathrm{C}$ for the $6005 \mathrm{~A}$ alloy. Heat treatments at $180 \mathrm{C}$ are performed on samples in the T4 state. Some 6056 plates in T4 state are transformed into T6 by a heat treatment at 180C for 8 hours. Heat treatments at $300 \mathrm{C}$ and $350 \mathrm{C}$ for various times ranging from 10 seconds to 20 days are performed on samples initially in the T6 state. Heat treatments are systematically followed by water-quenching and natural aging for at least one week before further artificial aging.

\subsection{Microstructure characterization of base alloys}

After standard polishing, the intermetallics and dispersoids particles are characterized using a Field Emission Gun Scanning Electron Microscope (FEG-SEM) operated at $15 \mathrm{kV}$ under electron backscattered mode. X-ray microtomography are performed at the TOMCAT beamline of the Swiss Light Source [50]. The sample is probed by X-ray beam tuned to $20 \mathrm{keV}$ using a double crystal multilayer monochromator. 1800 projections are recorded in absorption mode using the 16 bit PCO.edges CMOS detector coupled with a 20X optical magnifying lens to a 20 micrometer thick LuAG:Ce scintillator. The observed region is a cube of 260 $\mu \mathrm{m}$ side length with an isotropic voxel size of $325 \times 325 \times 325 \mathrm{~nm}^{3}$.

\subsection{Characterization of mechanical properties and damage}

\subsubsection{Macroscopic tensile tests}

Uniaxial tensile tests are performed on an universal Zwick $50 \mathrm{kN}$ testing machine under displacement control at constant velocity $(1 \mathrm{~mm} / \mathrm{min})$. The cylindrical samples, $4 \mathrm{~mm}$ in diameter, are extracted perpendicular to the primary direction. The initial gauge length is equal to $30 \mathrm{~mm}$. The initial yield stress $\sigma_{0}$ and the strain hardening parameters are extracted from the stress-strain curves based on an extended Voce law, i.e. $\partial \sigma / \partial \epsilon_{p}=\Theta-\beta \sigma+\Theta_{I V}$, where $\sigma$ is the true stress and $\epsilon_{p}$ is the true plastic strain. The 
strain hardening parameters are the dislocation storage rate $\Theta$, the dynamic recovery rate $\beta$ and the stage IV hardening $\Theta_{I V}$ following the extended Voce law, see [49]. The strain hardening exponent at necking is defined as $n_{\text {necking }}=\left.\frac{\epsilon}{\sigma} \frac{\partial \sigma}{\partial \epsilon}\right|_{\epsilon=\epsilon_{u}}$, where $\epsilon_{u}$ is the true strain at necking. The local true strain is defined as $\varepsilon_{l o c}=\ln \left(\frac{A_{0}}{A}\right)$, where $A_{0}$ and $A$ are the initial and current cross-section area, respectively. The true fracture strain is thus defined as $\varepsilon_{f}=\ln \left(\frac{A_{0}}{A_{f}}\right)$, where $A_{f}$ is the final cross-section area.

\subsubsection{Metallographic observations on broken samples}

Three broken tensile samples per alloy are polished down to mid-thickness along transverse section near the fracture surface: one in T4 state, one in T6 state and one in overaged state. FEG-SEM images at a magnification of 1500x are taken along a line perpendicular to the fracture surface every $0.2 \mathrm{~mm}$, see Fig. 2 . Particle fracture is the dominant nucleation mechanism with almost no interface decohesion. The surface and best fitting ellipse is recorded for every unbroken particle. If the particle is broken, it is reconstructed by merging all fragments and the best fitting ellipse and surface is recorded. About 10,000 particles have been analysed.

\subsubsection{In-situ tensile testing in X-ray microtomography}

A dedicated in-situ tensile testing machine described in [51] has been mounted on the rotation stage of the 3D tomography setup [52] of the ID15A beam line at the European Synchrotron Radiation Facility (ESRF) in Grenoble, France. The stage rotates at a constant speed while the tensile test is continuously performed at a displacement rate equal to $2 \cdot 10^{-7} \mathrm{~m} . \mathrm{s}^{-1}$ for the 6061 and 6056 alloys and at $5 \cdot 10^{-4} \mathrm{~m} \cdot \mathrm{s}^{-1}$ for the $6005 \mathrm{~A}$ alloy. The tensile force $F$ is recorded. Three mini notched tensile specimens, with yield stress close to 120 $\mathrm{MPa}$, outer diameter of $3 \mathrm{~mm}$, reduced diameter of $1 \mathrm{~mm}$ and notch radius of $1 \mathrm{~mm}$ are deformed up to fracture.

The data acquisition is made at regular discrete time steps, with a voxel size of $1.06 \mu \mathrm{m}^{3}$. The procedure used to separate the voids from the $\mathrm{Al}$ matrix is described in [47]. Only the central zone of the specimen is selected for the quantitative analysis of damage because it undergoes the largest stress triaxiality and thus the fastest damage rates [52]. A cube of $200 \mu \mathrm{m} \times 200 \mu \mathrm{m} \times 200 \mu \mathrm{m}$ is analyzed which is large enough to involve a sufficient number of voids and to be representative of the damage process, see further.

For each scanning step, the voids are distinguished from the Al matrix and the geometrical characteristics are recorded. A tracking procedure follows the cavities from one step to the next. The results of the tracking carried out on the Al 6056 specimen provides the experimental void growth rate. Experimental data were analysed by automatic tracking following the algorithm in [53], and double-checked by manual tracking. Only the cavities tracked for a minimum of 8 consecutive steps are used. The cavities leaving the analyzed box during straining are not considered. About one hundred tracks have been analyzed. 


\section{Cellular automaton micromechanics based damage model}

\subsection{Synopsis of the model}

A cellular automaton model has been developed based on an initial distribution of $n$ particles described by their position, dimensions (and thus shape) and orientation in a volume of material. A nucleation stress is associated to each particle following a distribution law which can be identified experimentally or predicted theoretically. The material is deformed under a prescribed stress and strain history which can be homogeneous or not at the scale of the volume. Nucleation, growth and coalescence of voids are described using analytical micromechanical models presented in sections 3.2 to 3.4. The model assumes no interactions between particles and/or voids during the nucleation and growth stages. The presence of the voids do not affect the applied stress and strain. At each deformation step, the nucleation, growth and coalescence of cavities are updated until a final failure criterion is verified (see section 3.5). The material is modeled using isotropic $\mathrm{J}_{2}$ flow theory. Since the volume fraction of second phase particles $f_{p}$ is close to $1 \%$, the reinforcement effect of these particles is weak as well as the loss of strength resulting from particle fracture. The matrix stress state is thus accurately described with the strain hardening parameters identified on the overall experimental flow stress (see section 2.3.1).

\subsection{Void nucleation model}

\section{Stress within the particle}

Particle fracture depends on the stress transfer in the particle and on the interface which itself depends on microstructural parameters such as particle size, shape and relative orientation to the loading direction [9]. Void nucleation via interface decohesion is not taken into account as particle fracture is the dominant failure mechanism [49], see also later.

The stress in the particle is decomposed as the sum of the stress in the matrix and of an additional stress transfer arising from the deformation mismatch between particle and matrix, which is calculated using Eshelby's theory with a plastic equivalent modulus for the matrix [54] as in the Beremin approach [9]. Hill [55] developed a self-consistent scheme for the problem of an ellipsoidal elastoplastic inclusion embedded in an infinite elastoplastic matrix. The elastoplastic behavior of the matrix is described by the effective moduli $\boldsymbol{L}^{\boldsymbol{e f f}}$ which links the macroscopic stress rates $\dot{\boldsymbol{\Sigma}}$ and the macroscopic strain rates $\dot{\boldsymbol{\varepsilon}}_{\boldsymbol{m a c r o}}$ as

$$
\dot{\Sigma}=L^{e f f}: \dot{\varepsilon}_{\text {macro }}
$$

The homogeneous stress rate in the inclusion $\dot{\boldsymbol{\sigma}}$ is then written as

$$
\dot{\sigma}=\dot{\Sigma}+L^{e f f}:\left(S^{-1}-I\right):\left(\dot{\varepsilon}_{\text {macro }}-\dot{\varepsilon}_{\text {inc }}\right)
$$

where $\boldsymbol{S}$ is Eshelby's tensor and $\dot{\boldsymbol{\varepsilon}}_{\boldsymbol{i n \boldsymbol { c }}}$ is the strain rate in the inclusion. The isotropic approximation of the effective moduli proposed by Berveiller and Zaoui [54] with the isotropic approximation of the effective moduli called $L^{\prime}$ writes

$$
L_{i j k l}^{\prime}=\mu^{*}\left[\frac{2 \nu^{*}}{1-2 \nu^{*}} \delta_{i j} \delta_{k l}+\delta_{i k} \delta_{j l}-\delta_{i l} \delta_{j k}\right]
$$


where $\delta_{i j}$ is the Dirac delta function. The expression for the secant "elasto-plastic" shear modulus $\mu^{*}$ and Poisson ratio $\nu^{*}$ are given in [54].

Introducing these secant elasto-plastic moduli into equation (2) gives the resulting interaction law relating finite quantities instead of their rates :

$$
\boldsymbol{\sigma}=\boldsymbol{\Sigma}+\boldsymbol{L}^{\prime}:\left(\boldsymbol{S}^{-1}-\boldsymbol{I}\right):\left(\varepsilon_{\text {macro }}-\varepsilon_{\text {inc }}\right)
$$

\section{Void nucleation model}

Particles are treated as brittle solids and fracture is assumed to occur when the maximum principal stress $\sigma_{\text {Part }}^{\max }$ (eq.(4)) reaches the critical stress $\sigma_{c}^{i}$ associated to this particle. The particle fracture stress distribution is assumed to follow a Weibull statistics given by

$$
P\left(\sigma_{\text {part }}^{\max }, V_{\text {part }}\right)=1-\exp \left(-\frac{V_{\text {part }}}{V_{0}}\left(\frac{\sigma_{\text {part }}^{\text {max }}}{\sigma_{w}}\right)^{m}\right)
$$

where $P$ is the probability of particle fracture for a given $\sigma_{\text {part }}^{\max }$ and volume of particle $V_{\text {part }}$, see Babout et al. [39] for example; $V_{0}$ is the reference particle volume and $\sigma_{w}$ and $m$ are the parameters of the distribution.

The nucleated void is assumed to be penny-shaped and its location is given by the intersection of the particle with a plane perpendicular to the maximum principal stress direction, see Fig. 3(a). The newly nucleated void is assumed to be ellipsoidal with main axis $a, b$ and $c$. The crack is assumed to appear at the middle of the particle. The initial void aspect ratio $W_{0}$ is set equal to 0.01 (with $c=W_{0} \sqrt{a b}$, see Fig. 3(a)). Lassance et al. [56] have shown that penny-shaped voids rapidly open and that the predicted void growth rate is independent of the choice of the initial porosity when imposing a value for $W_{0}$ sufficiently small.

\subsection{Void growth model}

The Rice and Tracey (R\&T) void growth model [5] has been selected. The original version was developed for a spherical void in an infinite, rigid perfectly plastic material under uniform remote strain $\epsilon_{i j}$ and stress $\sigma_{i j}$. The volume change is a function of the hydrostatic stress only while the change of shape is dictated by the deviatoric stress component. The strain rate field is expressed in terms of the principal components $\dot{\varepsilon}_{1}$ $\geq \dot{\varepsilon}_{2} \geq \dot{\varepsilon}_{3}$. A version of the model taking into account the aspect ratio evolution elaborated by Thomason [6] links the rate of change of the radii in the three directions of space $\left(R_{i}, \mathrm{i}=1,2,3\right)$ to the magnitude of $R_{\text {mean }}=\frac{R_{1}+R_{2}+R_{3}}{3}$ :

$$
\dot{R_{k}}=\left((1+E) \dot{\varepsilon_{k}}+\sqrt{\frac{2}{3} \dot{\varepsilon}_{l} \dot{\varepsilon}_{l}} D\right) R_{\text {mean }}
$$

where $D$ is given by $D=\alpha T^{0.25} \exp \left(\frac{3}{2} T\right)$ for $T \leq 1$, and $D=\alpha \exp \left(\frac{3}{2} T\right)$ for $T \geq 1$, with the stress triaxiality $T$ and $\alpha$ equal to 0.427 as corrected by Huang [57]. Here $\alpha$ can be taken as a free parameter that can be adjusted to account for the approximations in the model such as the absence of strain hardening. The factor $D$ characterizes the dilatational contribution and $(1+E)$ characterizes the change of aspect ratio. The factor $(1+E)$ is fixed and equal to $\frac{5}{3}$ as initially predicted by Rice and Tracey [5], see [58] for a more elaborated expression not used in this study. 
This void growth model has been initially developed for voids with the main axes aligned with the principal loading directions $\left(\Sigma_{1}, \Sigma_{2}, \Sigma_{3}\right)$. An heuristic procedure is proposed in order to estimate the void growth rates in the case of an ellipsoidal void under general loading conditions. The principal radii of the ellipsoidal void are replaced by the three intersections of the void with the principal stress directions. This equivalent void is then assumed to follow the growth model given by equation (6), see Fig. 3(b). The void growth procedure is detailed in the Appendix.

Since voids nucleate by particle cracking rather than by decohesion, a freshly nucleated void is initially penny-shaped and the mode of deformation is dominated by opening and blunting of the void/crack tip [59]. At low $\mathrm{T}$, the growth model given by equation (6) predicts a decrease of the void size in the transverse directions $\Sigma_{2}$ and $\Sigma_{3}$ while, in reality, the particle constraints the transverse contraction same as for the case where the particle is inside the cavity as analysed by [56]. A slight modification of the model has thus been made. The term controlling the transverse contraction due to the shape changing component of the remotely applied deformation field is deleted for the transverse directions $\left(1+E=0\right.$ for $\left.\dot{R}_{2}, \dot{R}_{3}\right)$. This version of the model will be referred next as the "constraint" growth model.

\subsection{Void coalescence model}

The void coalescence condition developed by Thomason is used in its extended form $[6,17,30]$ :

$$
\frac{\Sigma_{n}}{\sigma_{y}}=\left(1-\chi_{e f f}^{2}\right)\left[\alpha_{T h}\left(\frac{1-\chi_{e f f}}{W_{e f f} \chi_{e f f}}\right)^{2}+1.24 \frac{1}{\sqrt{\chi_{e f f}}}\right]
$$

where $\Sigma_{n}$ is the overall stress component normal to the localization plane; $\chi_{\text {eff }}$ and $W_{\text {eff }}$ are the effective void aspect ratio and effective void spacing respectively defined in eq. (8) and (9), see later. The parameter $\alpha_{T h}$ depends on the strain hardening exponent $n$ as proposed by Pardoen and Hutchinson [17] : $\alpha_{T h}=$ $0.1+0.217 n+4.83 n^{2}$.

The coalescence model has been developed for identical neighboring voids having the ligament joining their centers normal to the principal loading direction $\Sigma_{1}$. This is not representative of an actual microstructure. A generalization has been proposed by Scheyvaerts et al [30] in order to account for the orientation of the inter-void ligament. The equivalent maximum in-plane tensile stress $\Sigma_{\text {Plane }}^{1}$ is found using a simple procedure detailed in [60]. To apply this procedure, the two voids are transformed into an effective configuration made of two identical voids (Fig. 3 (c)) in order to define $W_{\text {eff }}$ and $\chi_{\text {eff } f}$.

The later is determined from the center-to-center distance $L_{c e n t e r}$ and $R_{c e n t e r, 1}$ and $R_{c e n t e r, 2}$ the radii measured along the center-to-center direction (Fig. 3 (c)) as

$$
\chi_{e f f}=\frac{R_{c e n t e r, 1}+R_{\text {center }, 2}}{L_{\text {center }}} .
$$

The effective void aspect ratio $W_{\text {eff }}$ is taken as a mean of the aspect ratio of the two neighboring voids and is defined as :

$$
W_{e f f}=\frac{1}{2}\left(\frac{R_{p e r p, 1}}{\sqrt{a_{1} b_{1}}}+\frac{R_{p e r p, 2}}{\sqrt{a_{2} b_{2}}}\right)
$$


where $\left(a_{1}, b_{1}\right)$ and $\left(a_{2}, b_{2}\right)$ are the half-axes of the two ellipses resulting from the cross section of each void taken in the transverse direction to the in-plane stress direction. The equivalent voids resulting from this procedure are shown in Fig. 3(d), where $R_{\text {center }}=\chi_{\text {eff }} \frac{L_{c e n t e r}}{2}$ and $R_{\text {perp }}=W_{\text {eff }} R_{\text {center }}$. Furthermore, the minimum distance between each void is checked to be larger than zero in order to ensure no overlapping. This heuristic extension has been partly assessed by [30], although only for spheroids of identical dimension. This extension is certainly an open area for improvement. The local displacements of the centroid of the particles and cavities during a strain increment are calculated by interpolation of the FE displacement field.

Once the coalescence criterion is satisfied for two voids, failure of the inter-void ligament is modelled by merging the two voids and replacing them by the minimum ellipsoid that envelops them both (Fig. 3 (e)). In this case, the axis of the cavity can be significantly out of the principal loading direction justifying the correction for non aligned ellipsoid (see Appendix). The coalescence criterion is then checked for this new void and each neighboring void, allowing the coalescence process to locally flourish. This procedure neglects the small additional strain needed to bring the two voids from the onset of coalescence to final coalescence (see [37] for discussion of details). More advanced versions of a coalescence model accounting for the shear component along the localization plane [36] will be considered in future extensions.

\subsection{Final failure criterion}

Several authors $[61,62,17]$ have shown the inadequacy of models based on a critical porosity value to predict the strain to failure. Indeed, the porosity at coalescence is found to depend on the initial void volume fraction $f_{0}$, the flow properties and stress state and is thus not a "universal" value. The onset of coalescence in a small material volume as predicted by eq.(7) is not a sufficient condition for fracture in the case of heterogeneous materials. Thomson et al. [16] have shown that coalescence of voids within a cluster consisting of a few particles is a stable event while the collapse of inter-cluster ligaments leads to imminent material failure. This inter-cluster ligaments collapse is associated to a significant and sudden increase of the porosity (i.e. a large rate of porosity increase). An empirical failure criterion has thus been chosen here to

be a critical rate of porosity increase $\left.\frac{\partial f}{\partial \epsilon^{p}}\right|_{c}$. The physical meaning of this critical rate of porosity increase is associated to voids linkage over a macroscopic scale that triggers catastrophic ductile failure. In a more sophisticated model, crack propagation from the most critical coalesced patch of voids would be the most correct approach but this goes out of the scope of the current state of this work.

\subsection{Summary of the parameters of the model}

The following set of parameters is needed to run a simulation with the cellular automaton model (see Fig. 4). The microstructural parameters, i.e. particles and initial cavities parameters ${ }^{1}$ :

- the positions $x_{i}, y_{i}, z_{i}$;

- the dimensions $R_{x, i}, R_{y, i}, R_{z, i}$;

- the three angles which define the orientation in space $\theta_{1, i}, \theta_{2, i}, \theta_{3, i}$.

The flow properties of the matrix : 
- the initial yield stress $\sigma_{0}$;

- the extended Voce law parameters : $\Theta, \beta, \Theta_{I V}$.

The damage model parameters :

- the Weibull distribution parameters ${ }^{2}: V_{0}, \sigma_{w}, m$;

- the $\alpha$ parameter of the $R \& T$ model which is experimentally measured to correct for the limitations of the model : $\alpha_{\text {growth }}$;

- the critical rate of porosity increase $\left.\frac{\partial f}{\partial \epsilon^{p}}\right|_{c}$.

\subsection{Numerical procedures}

A multi-scale approach combines FE simulations and the use of the cellular automaton model at a local scale, see Fig. 4. FE simulations of the tensile specimens are conducted with the general purpose software Abaqus [63] using $J_{2}$ flow theory and hardening law prescribed in section 2.3.1. The aim is to transfer to the cellular automaton the local stress and strain variations accounting here for specimen necking. The FE procedures are fully standard and convergence of the results was carefully checked. A Matlab [64] program has been written for the cellular automaton $(\mathrm{CA})$. For each deformation step, one iteration of the $\mathrm{CA}$ is performed, see Fig. 4. Fig. 3(f) shows the full representative volume element (RVE) used in the cellular automaton for a local strain $\varepsilon_{l o c}=0.25$. It appears from this figure that the size of the RVE must be large enough to capture the local variation of spatial distribution of voids and particles inducing local coalescence processes (voids in grey in Fig. 3(f)) and to enable damage percolation over a macroscopic scale that triggers catastrophic ductile failure.

\section{Results and discussion}

\subsection{Microstructure and mechanical properties}

The reconstructed X-ray microtomography volume of the three alloys in their initial states (as observed with $0.3 \mu \mathrm{m}$ voxel size microtomography at the TOMCAT beamline in SLS) are illustrated in Fig. 5. Particles and initial porosities are respectively highlighted in blue and red. Fig. 5(b,c) presents the size distribution for the intermetallic particles based on SEM micrographs and on 3D X-ray microtomography images. The equivalent diameter $D_{e q}$ corresponds to the diameter of a sphere with the same volume as the particle. Table 2 gives the corresponding averaged parameters. The differences between the two characterization techniques are probably due to the difference of resolution. The SEM micrographs were taken at a magnification of 2000X allowing a statistical analysis of particles larger than about $500 \mathrm{~nm}$. The X-ray microtomography images have a voxel size of $325 \times 325 \times 325 \mathrm{~nm}^{3}$ (section 2.2) allowing to reliably identify particles larger than about $700 \mathrm{~nm}$ (i.e. 2 voxels). Indeed, it will be shown subsequently (section 4.2.1, Fig. 7) that the particles

\footnotetext{
${ }^{1}$ Identified from X-ray microtomography data of the base alloys (section 2.2)

${ }^{2}$ Identified in order to satisfy the Weibull distribution (section 2.3.2)
} 
that will actually lead to damage are essentially the largest one $\left(D_{e q}>1 \mu m\right)$. Thus, the exact identification (size, position, number density) of the smallest particles is of secondary importance for the prediction of the fracture strain by the cellular automaton model. Furthermore, the SEM micrographs allow the observation of the near surface of the polished sample only. As the particles are not necessarily intersected close to the equator, the value of the equivalent diameter measured in the plane section is smaller than the actual $3 \mathrm{D}$ value and the $2 \mathrm{D}$ equivalent diameter has thus been multiplied by a stereological factor $\frac{4}{\pi}$. Globally, Fig. $5(\mathrm{~b}, \mathrm{c})$ shows that the trends remain in good agreement, irrelevant of the characterization technique. In particular Table 2 indicates that the particle volume fraction of all three alloys is close to $1 \%$ (the value for the $6005 \mathrm{~A}$ is underestimated due to the small size of the particles in that alloy). All alloys have a particle size shape factor close to 2 that is measured as slightly lower by SEM, but 2D imaging is not ideal for the identification of this parameter. The mean equivalent diameter is $\sim 1 \mu \mathrm{m}$ for the $6005 \mathrm{~A}$ alloy, $\sim 2 \mu \mathrm{m}$ for the 6061 alloy and slightly above $2 \mu \mathrm{m}$ for the 6056 alloy which includes a high fraction of very large particles $\left(D_{e q}>5 \mu m\right)$ as demonstrated in the inset of Fig. 5(b).

Initial porosities are observed in the $\mathrm{Al} 6056$ and $\mathrm{Al} 6061$ both in the X-ray microtomography images and SEM micrographs. None of these porosities are observed in the $\mathrm{Al} 6005 \mathrm{~A}$ at the resolution of the Xray microtomography images. The initial porosity $f_{0}$, equivalent diameter and shape factor are provided in Table 3. Some of these cavities originate from the gathering during Al solidification of the hydrogen easily dissolved in liquid $\mathrm{Al}[65]$ while others originate from the fracture of intermetallic particles during the forming process.

Fig. 6 presents the yield stress $\sigma_{0}$ of the three alloys as a function of the various heat treatments durations. In each alloy, the yield stress peak corresponds to the T6 state. Fig. 1 summarizes the results for the three alloys in terms of true fracture strain (Fig. 1.a) and of true strain at onset of necking (Fig. 1.b) as a function of the yield stress. While the fracture strains are very different for the three alloys, the necking strains follow the same "banana" shaped trend with limited exceptions. This clearly indicates that uniform elongation is absolutely not representative of the true fracture strain. Fig. $1(\mathrm{c}, \mathrm{d})$ provide the dislocation storage rate $\theta_{0}$ and parameter $\beta$. These parameters are needed to account for strain hardening in the model (Fig. 4, input $3)$.

\subsection{Damage evolution: experimental results and model parameter identification}

\subsubsection{Void nucleation}

The magnitude and distribution of particle fracture stress can be identified in the following way. Metallographic observations of the polished sections of broken specimens (cf. section 2.3.2) are used instead of in-situ microtomography tests because the void nucleation kinetics is not accurately captured with the resolution of about $1 \mu m^{3}$ (cf. section 2.3.3) when compared to the particle size ( 1 to $4 \mu \mathrm{m}$ ). The maximum principal stress $\sigma_{\text {Part }}^{\max }$ in each particle can be estimated using equation (4) based on the overall stress and strains calculated by standard FE simulations at the location of the particles. If a given observed particle is broken, the critical stress at which void nucleation has occurred lies between 0 and $\sigma_{\text {Part }}^{\max }$. The nucleation stress of 
the broken particles is said to be interval-censored and falls in the interval $\left(0, \sigma_{\text {Part }}^{\max }\right]$. On the other hand, if a given particle is not broken, it can only be concluded that the critical stress at which void nucleation would occur is larger than $\sigma_{\text {Part }}^{\max }$. The nucleation stress of the unbroken particles is said to be right-censored and falls in the interval $\left(\sigma_{\text {Part }}^{\max }, \infty\right]$. The exact nucleation stress of the $i^{t h}$ particle is thus not exactly known but is associated to an interval $\left(0, \sigma_{\text {Part }}^{\max }\right]$ or $\left(\sigma_{\text {Part }}^{\max }, \infty\right]$. A mathematical iterative procedure is needed in order to retrieve from these data, the nucleation stress distribution. A set of Weibull parameters is selected and for all the particles used to generate the curve of Fig. 7, a critical stress $\sigma_{c}^{i}$ is assigned to each particles. $\sigma_{\text {Part }}^{\max }$ is calculated for each particle and if the critical stress $\sigma_{c}^{i}$ is larger than $\sigma_{\text {Part }}^{\max }$, the particle is considered as broken. The criterion is checked for all particles and the prediction of "broken" versus "unbroken" is compared to the experimental record. This procedure is repeated for several sets of Weibull parameters and the best parameters are found to be $\sigma_{w}=1200 \mathrm{MPa}, m=7$, and $V_{0}$ corresponding to an equivalent diameter $d_{0}=2.2 \mu \mathrm{m}$.

A very strong assumption is made regarding the void nucleation stress: the magnitude and distribution of void nucleation stress is taken identical for the three alloys, depending only on the particle size. Alternatively, different critical stress distribution could have been identified but, for the sake of simplicity, and mainly to focus on the primary issue of particle size and spatial distribution, it was decided to aggregate all data together. This implicitly assumes that the intermetallic particles in the three alloys have a similar structure and mechanical behaviour.

Fig. 7 shows the evolution of the fraction of broken particles as a function of particles size as observed experimentally and as obtained with the best Weibull parameters $\left(\sigma_{w}=1200 \mathrm{MPa}, m=7\right.$, and $V_{0}$ corresponding to an equivalent diameter $d_{0}=2.2 \mu \mathrm{m}$ ) found in section 3.2. The predictions agree with the experimental evolution. Consequently, a Weibull distribution using the same parameters for the 3 alloys seems to be a reasonable approximation partly validating our initial choice. The fraction of broken particles increases with particle size. Fig. 7 also shows that smaller particles give rise to void nucleation in the 6005A alloy (Fig. 5(b)), but at relatively large equivalent strains (as it will be shown in section 4.3) corresponding to sufficiently large stress needed to break small particles. The alloy 6061 presents an intermediate behavior consistent with its reduced proportion of large particles (Fig. 5(b)).

\subsubsection{Void growth}

The results of the tracking carried out on the $\mathrm{Al} 6056$ specimen provides the experimental void growth rate for each cavity (Fig. 8(a)), with clear dispersion in the growth kinetics.

Fig. 8(b) shows a comparison of the experimental and predicted evolution of the relative rates of change $R_{e q} / R_{e q, 0}$ of the equivalent radius of the voids. These rates have been averaged over all voids. The predictions of the R\&T (cf. eq 6, section 3.3) in the original and "constraint" versions are provided in Fig. 8(b) for the void growth, and in Fig. 8(c) for the void aspect ratio evolution. The void aspect ratio $W_{\text {void }}$ is defined as $W_{\text {void }}=\frac{R_{1}}{\sqrt{R_{2} R_{3}}}$, see section 3.3. Knowing the values of $T$ and of the strain around the cavity for each microtomography measurement, an inverse procedure is carried out in order to calculate the value of $\alpha$ (eq. 
6 ) which best corresponds to the experimental relative growth rate for each version of the model. The best value associated to the void growth model is $\alpha \approx 0.84$. With $\alpha \approx 0.84$, one can observe that the rate of change of the void aspect ratio is then significantly over predicted (Fig. 8(c)). The same procedure has been carried out for the "constraint" growth model. In this case, the best value for the parameter $\alpha$ is found to be 0.57 , much closer to the theoretical value 0.427 [57], and the rate of change of the void aspect ratio is more consistent with the experimental data. Landron [47] and Lecarme et al. [53] have largely discussed several possible reasons that justify why $\alpha$ can be different from the theoretical value. Now, this value $\alpha=0.57$ and constraint growth model are used for all other materials and all thermal treatments.

\subsection{Exploitation and assessment of the model}

The model is assessed in two steps. First, by direct comparison of the full model with microtomography results obtained on the three alloys with a similar yield strength. Second, all heat treatment conditions are modelled and compared to the experimental $\epsilon_{f}$, as provided in Fig. 1.a.

The growth model is now coupled to the nucleation and coalescence model, which was not the case in Fig. 8.

Fig. 9 shows the evolution of the void volume fraction $f$. The predicted evolution of $f$ agrees with the experimental evolution. The microstructural parameters used to run these simulations (see section 3.6) are identified from the X-ray microtomography data of section 2.2 , with a resolution of about $0.034 \mu \mathrm{m}^{3}$. Indeed, the resolution of the first scan of the material (i.e. in its undeformed state) of in-situ microtomography tests is about $1 \mu m^{3}$ (cf. section 2.3.3) and is not sufficient to accurately capture the particle size distribution ranging mainly between 1 to $4 \mu \mathrm{m}$. This explains why the initial void volume fraction predicted by the model is different from the initial void volume fraction measured during in-situ microtomography (see Fig. 9.b). However, the fact that the predicted $f$ agrees with the experimental evolution is an indication that the RVE has a sufficient size from a statistical viewpoint to reproduce the experiments.

For the alloy $6005 \mathrm{~A}$, the rapid increase of $f$ is predicted later than in the experiments. This could have been corrected by selecting different void nucleation Weibull parameters for each alloy. However, using the same nucleation stress distribution versus particle size, i.e. neglecting possible differences of particles properties between the three alloys, highlights the major effect of particle size distribution on the fracture strain.

Fig. 10 shows in more details results from the model applied to the $\mathrm{Al} 6056$ alloy for three heat treatments (namely $\mathrm{T} 6, \mathrm{~T} 4$ and overaged with $\sigma_{0} \simeq 60 \mathrm{MPa}$ ) and results for the three alloys in the $\mathrm{T} 6$ state. The point on each curve corresponds to the predicted fracture strain, i.e. the strain at which the critical rate of porosity $\dot{f}_{c}=\left.\frac{\partial f}{\partial \epsilon_{l o c}}\right|_{c}$ is satisfied.

Results obtained with the model for the three alloys in the T6 state explain the large differences in $\varepsilon_{f}$. Fig. 10(b) shows a fast increase of the fraction of broken particles, i.e. a large nucleation rate, for the $\mathrm{Al} 6056$ and $\mathrm{Al}$ 6061. This fast increase corresponds to very large particles which break at very low strain. Very large particles are present in larger proportion in the alloy 6056, see inset of Fig. 5(b), and it exhibits the highest 
fraction of broken particles. On the opposite, this initial fast increase of the fraction of broken particles is much lower for the $\mathrm{Al}$ 6005A due to the absence of large particles in this alloy, see inset of Fig. 5(b). After a few percents of deformation, the increase of the fraction of broken particles reaches a linear evolution. The rate of increase in this linear regime is the highest for $\mathrm{Al}$ 6056, and higher for $\mathrm{Al} 6061$ compared to $\mathrm{Al}$ 6005A. This is consistent with the particle size distribution (see Fig. 5(c)), similarly to what was concluded from Fig. 7. Fig. 10(c) shows that the differences in the fractions of coalesced voids between the three alloys correlate with the trends in void nucleation. This is due to the fact that more void nucleation increases the void density, and this locally increases probability that two voids satisfy the coalescence criterion. Fig. 10(d) shows the variation of the total number of voids, i.e. the sum of the initial cavities and nucleated voids minus the number of coalescence events. In each case, the total number of voids exhibits first an increase, as it is dominated by void nucleation, up to some point where voids linkage spread over. At this point, the number of voids starts to decrease and the void volume fraction increases very fast (Fig. 10(a)).

Predictions of the model applied to the Al 6056 alloy for three heat treatments (T6,T4,OA) explain why, for a given alloy, $\varepsilon_{f}$ decreases with increasing $\sigma_{0}$. This well known evolution [49] is associated to the larger strains needed to reach the same stress level in particles surrounded by a soft matrix (Fig. 10(b)) and is consistent with a stress criterion for the fracture of the particles. The density of voids and the number of coalescence events, at a given strain, is thus lower if $\sigma_{0}$ decreases (see Fig. 10(c,d)).

If the final failure criterion is chosen as a given fraction of coalesced voids (10\% for exemple, see Fig. 10(c)) or as the beginning of the fast decrease in the total number of voids (Fig. 10(d)), the predicted $\varepsilon_{f}$ is different, but the differences between the three materials or between the heat treatments exhibit the same trend. This is due to the fact that the fast increase of void volume fraction is associated to voids linkage over a macroscopic scale that triggers catastrophic ductile failure.

The model is now applied to predict the evolution of $\varepsilon_{f}$ with $\sigma_{0}$ for all heat treatments conditions. The

critical $\dot{f}, \dot{f}_{c}$, was identified as equal to $24\left(\dot{f}=\frac{\Delta f}{\Delta \varepsilon_{L o c}}\right.$, with $\left.\Delta \varepsilon_{\text {Loc }}=0.01\right)$ to capture one data point of one of the three alloys and then kept constant for all other conditions. The results are shown in Fig. 11. The model nicely captures the differences in $\varepsilon_{f}$ among the three alloys as well as the decrease of $\varepsilon_{f}$ with the increase of $\sigma_{0}$. The difference between the alloys is thus primarily related to the particle size distribution. Once again, the cellular automaton model parameters have been identified directly from experimental data with a clear physical meaning with no additional fitting or adjustment of tuning parameters except for $\dot{f}_{c}$ and $\alpha$ (with for the last one a value that remains close to the theoretical one).

\subsection{Sensitivity analysis}

Fig. 12 presents the sensitivity analysis of the CA to the inclusion orientation and spatial distribution. The analysis also shows the effect of using the two versions of the void growth model and the effect of the void aspect ratio definition used in the Thomason criterion. The sensitivity analysis has been performed for the $\mathrm{Al} 6056$ alloy under the three different heat treatments (namely $\mathrm{T} 6$, T4 and overaged with $\sigma_{0} \simeq 60 \mathrm{MPa}$ ) 
which have already been studied in Fig. 10. The version of the CA developed in section 3, and applied to the microstructure extracted form X-ray microtomography volume, will be referred as the "full model". Each effect has been tested independently.

\section{Sensitivity to inclusion orientation}

The sensitivity of the model to inclusion orientation has been analysed by testing the extreme case for which all the particles have their major axis aligned with the main loading direction, keeping their volume and spatial distribution unchanged. Fig. 12 shows that for this configuration, the predicted $\varepsilon_{f}$ is nearly unchanged in the T6 state, slightly modified in the T4 state and lower in the overaged case by $15 \%$. The orientation of the particles mainly affects the void nucleation stage. When the major axis of the particles is aligned with the main loading direction, the load transfer arising from the deformation mismatch between particle and matrix increases (see section 3.2), as already shown in Ref. [9]. In the T6 and T4 cases, void nucleation is already quite fast (see Fig. 10(b)) in any cases but in the overaged case the impact is more significant. The increased void nucleation rate due to the reorientation of the particles has thus a small to moderate impact on $\varepsilon_{f}$.

\section{Sensitivity to spatial distribution of inclusions}

The spatial distribution of the particles used in the full model has been directly extracted from microtomography. A periodic cubic arrangement of particles has been chosen to study the effect of particle distribution on the damage process as a sort of extreme ideal case. The particles shape and orientation and the overall particles volume fraction remain unmodified compared to the full model. Fig. 12 shows that there is a very large effect of the particle distribution on the predicted $\varepsilon_{f}$. Spatial distribution of particles influences the void coalescence process due to its effect on the local void spacing. On the opposite, the spatial distribution doesn't impact void nucleation and growth since interactions are neglected. The increased ductility with the periodic distribution can be explained by the fact that the voids linkage percolating over a sufficient length scale to trigger catastrophic ductile fracture is significantly postponed. Indeed, as shown in Fig. 5(a), the actual spatial distribution of particles is not homogeneous, with some local clustering. The full analysis of the effect of particles spatial distribution, for instance using percolation indicator, goes beyond the scope of the present analysis but this result indicates the need for further investigation on this topic in order to define the right topological indicators to characterize the microstructure heterogeneity with respect to this specific mechanism.

\section{Sensitivity to initial porosity}

Fig. 12 shows that the initial porosity has a large effect on the predicted $\varepsilon_{f}$. Indeed, even though $f_{0}$ is very low (see Table 3), the cavities which are initially present in the material are quite large compared to the penny-shaped voids nucleated by particle fracture. The presence of an initial porosity facilitates voids linkage over a sufficient length scale to trigger earlier catastrophic ductile failure. The effect is more important in the overaged case since void nucleation is a dominant phase in the T6 and T4 cases (see Fig. 10(b)), attenuating the impact of the presence of an initial porosity. Now, looking back at the comparison between the 3 alloys 
tested experimentally, the initial porosity is also a factor that can justify the large difference in fracture strain among the three alloys as $\varepsilon_{f}$ clearly decrease with increasing $f_{0}$, see Table 3 .

\section{Sensitivity to the void growth model}

As explained in section 3.3, the R\&T void growth model has been slightly modified to take into account the effect of the presence of the particle on void growth. Furthermore, the best value for the parameter $\alpha_{\text {growth }}$ has been shown to be 0.57 instead of the theoretical value 0.427 . This modified void growth model has been shown to give a better agreement with the experimentally observed void growth (section 4.2.2). In order to assess the significance of this correction, the model has been applied with the original version of the R\&T void growth model (i.e. $\alpha_{\text {growth }}=0.427$ and no effect of the particle on the void growth). Fig. 12 shows that there is a strong increase of the predicted $\varepsilon_{f}$ without the correction. Indeed, reducing the parameter $\alpha_{\text {growth }}$ from 0.57 to 0.427 induces a slower void growth rate retarding fracture. Furthermore, at low stress triaxiality, the original growth model predicts a decrease of the void size in the transverse directions while, in reality, the particle constraints the transverse contraction (see section 3.3). This delays the coalescence process as the relative void spacing is reduced and this shows that fracture in these alloys is also partly dominated by the void growth phase.

\section{Sensitivity to coalescence model}

A heuristic extension of the Thomason criterion has been used in order to define an effective void aspect ratio $W_{\text {eff }}$ (see section 3.4). As mentioned previously, this extension has been partly assessed in [30], although only for spheroids of same dimension. To test the impact of the assumptions made to estimate $W_{\text {eff }}$, the effective void aspect ratio $W_{\text {eff }}$ used in eq.(7) has been fixed equal to 1 as an extreme case. In other words, the coalescence criterion is evaluated as if the two voids were spherical. This extreme assumption is used to evaluate the void coalescence criterion only; the shape of the actual void is used in the rest of the model. Fig. 12 shows that the predicted $\varepsilon_{f}$ remains nearly unchanged in the overaged case. In this ductile condition, a significant void growth occurs before the coalescence criterion is met with a shape that gets close to equiaxed, see Lassance et al. [56] for more detailed analysis of the void growth and coalescence of initially penny-shaped voids. In the T6 state, void nucleation is the dominant stage (see Fig. 10(b)) and coalescence events occurs at smaller strains (see Fig. 10(c)). Since the void growth stage is reduced, the opening of the penny-shaped voids is reduced and the aspect ratio is significantly smaller than one when coalescence starts.

As a conclusion to the sensitivity analysis, it shows first that the particle distribution is the most significant factor. It also shows that it is important to test the validity of the three elements of the model; void nucleation, void growth and void coalescence as they can play a first order role depending on the hardening of the matrix.

\section{Conclusion}

The hardening and fracture properties of three 6xxx series aluminum alloys have been measured for a wide variety of heat treatment conditions. The tensile tests revealed major differences in the fracture strain for the same yield strength, even though the volume fractions of second phase particles are very similar ( $\sim 1 \%)$. The fracture strain decreases with increasing yield strength with about the same slope for each alloy. A cellular 
automaton model, based on simple micromechanical models for void nucleation, growth and coalescence taking into account microstructural heterogeneities is presented. It provides very good predictions regarding the different fracture strain variations with only two fitting parameters, out of which one is close to the theoretical estimate.

The main conclusions of the study are the following :

- the fracture strain is primarily dictated by the effect of particle size distribution with the alloy exhibiting the smallest particles being the most ductile;

- the use of the same magnitude of nucleation stress and distribution with particles sizes for the three alloys is sufficient to deliver adequate predictions indicating that the intermetallic particles properties must be relatively similar;

- particle spatial distribution when compared to periodic distribution plays also a first-order effect on controlling the ductility;

- the presence of pre-existing voids has also a first order effect on the predicted fracture strains;

- the experimental scattering in the void growth rate in aluminum is significant, such as recently concluded for a titanium alloy (see Lecarme et al[53]);

- a cellular automaton model involving simple damage criteria is a relevant approach to address the fracture strain prediction in the case of a metallic alloy exhibiting significant heterogeneity effects.

\section{Acknowledgements}

The authors would like to thank the ESRF for the provision of synchrotron radiation at the ID15A beamline. The authors acknowledge the financial support of the Interuniversity Attraction Poles Program from the Belgian State through the Belgian Policy agency, contract IAP7/21 INTEMATE. F. Hannard acknowledges the financial support of the FRIA, Belgium. The collaboration between UCL and INSA-Lyon is financed by a Tournesol 2013 project.

\section{Appendix}

The void growth model has been developed for voids with the main axes aligned with the principal loading directions $\left(\Sigma_{1}, \Sigma_{2}, \Sigma_{3}\right)$. An heuristic procedure is proposed in order to estimate the void growth rates in the case of an ellipsoidal void under general loading conditions. The principal radii of the ellipsoidal void are replaced by the three intersections of the void with the directions of the principal stress $\left(R_{1}, R_{2}, R_{3}\right.$, see Fig. 13). This equivalent void is then assumed to follow the growth model given by equation (6). The problem can now be treated as the stretching of an ellipsoid along three arbitrary directions (see Fig. 13) which requires an eigenvalue solution where the new void semi-axes and orientation is defined by the eigenvalues and the 
eigenvectors. This procedure for the arbitrary stretching of an ellipsoid is detailed in [60]. Using this void growth model, the void will grow and reorient itself to be aligned with the preferential loading direction. If the directions of the semi-axes and principal loading directions are aligned, the void will not rotate. The center of the ellipsoid remains unchanged. 


\section{References}

[1] K. Tanaka, T. Mori, T. Nakamura, Cavity formation at the interface of a spherical inclusion in a plastically deformed matrix, Philos Mag 21 (170) (1970) 267-279.

[2] A. Argon, J. Im, R. Safoglu, Cavity formation from inclusions in ductile fracture, Metall Mater Trans A 6 (4) (1975) 825-837.

[3] A. A. Benzerga, J.-B. Leblond, Ductile fracture by void growth to coalescence, in: H. Aref, E. van der Giessen (Eds.), Adv App Mech, Vol. 44 of Adv App Mech, Elsevier, 2010, pp. 169 - 305.

[4] F. A. McClintock, A criterion for ductile fracture by the growth of holes, J. Appl. Mech. 35 (1968) $363-371$.

[5] J. R. Rice, D. M. Tracey, On the ductile enlargement of voids in triaxial stress fields, J Mech Phys Solids 17 (3) (1969) 201-217.

[6] P. Thomason, Ductile Fracture of Metals, Pergamon press, 1990.

[7] A. Pineau, T. Pardoen, 2.06 - failure of metals, in: I. M. R. Karihaloo (Ed.), Comprehensive Structural Integrity, Pergamon, Oxford, 2007, pp. $684-797$.

[8] T. Pardoen, F. Scheyvaerts, A. Simar, C. Tekog̃lu, P. Onck, Multiscale modeling of ductile failure in metallic alloys, C R Phys 11 (3-4) (2010) $326-345$.

[9] F. Beremin, Cavity formation from inclusions in ductile fracture of A508 steel, Metall Mater Trans A 12 (1981) 723-731.

[10] D. Lassance, D. Fabrègue, F. Delannay, T. Pardoen, Micromechanics of room and high temperature fracture in 6xxx Al alloys, Prog. Mater Sci. 52 (1) (2007) 62-129.

[11] S. Bugat, J. Besson, A. Pineau, Micromechanical modeling of the behavior of duplex stainless steels, Comput. Mater. Sci. 16 (1-4) (1999) $158-166$.

[12] P. P. H. H. J. E. E. Maire, D.S. Wilkinson, A.S. Kahn (Ed.), Proceedings of 6th International Symposium on Plasticity and its Current Applications, Neet Press, Fulton, MD.

[13] E. Roux, M. Shakoor, M. Bernacki, P.-O. Bouchard, A new finite element approach for modelling ductile damage void nucleation and growthanalysis of loading path effect on damage mechanisms, Model. Simul. Mater. Sci. 22 (7) (2014) 075001.

[14] A. Needleman, A. Kushner, An analysis of void distribution effects on plastic flow in porous solids, Eur J Mech A-Solids 9 (3) (1990) 193-206. 
[15] Y. Huang, The role of nonuniform particle distribution in plastic flow localization, Mech Mater 16 (3) (1993) $265-279$.

[16] C. Thomson, M. Worswick, A. Pilkey, D. Lloyd, Void coalescence within periodic clusters of particles, J Mech Phys Solids 51 (1) (2003) 127-146.

[17] T. Pardoen, J. W. Hutchinson, An extended model for void growth and coalescence, J Mech Phys Solids 48 (12) (2000) 2467-2512.

[18] P. Achon, Comportement et tenacite d'alliages d'aluminium a haute resistance, 1994.

[19] V. Tvergaard, Interaction of very small voids with larger voids, Int J Solids Struct 35 (30) (1998) $3989-4000$.

[20] D. Fabrègue, T. Pardoen, A constitutive model for elastoplastic solids containing primary and secondary voids, J Mech Phys Solids 56 (3) (2008) 719-741.

[21] S. Yerra, C. Tekoglu, F. Scheyvaerts, L. Delannay, P. V. Houtte, T. Pardoen, Void growth and coalescence in single crystals, Int J Solids Struct 47 (78) (2010) 1016 - 1029.

[22] A. L. Gurson, Continuum theory of ductile rupture by void nucleation and growth,1. Yield criteria and flow rules for porous ductile media, J. Eng. Mater. Technol. 99 (1) (1977) 2-15.

[23] M. Gologanu, J.-B. Leblond, G. Perrin, J. Devaux, Recent extensions of Gurson's model for porous ductile metals, in: P. Suquet (Ed.), Continuum Micromechanics, 1997, pp. 61-130.

[24] J. Besson, C. Guillemer-Neel, An extension of the Green and Gurson models to kinematic hardening, Mech. Mater. 35 (2003) 1-18.

[25] K.-C. Liao, J. Pan, S. Tang, Approximate yield criteria for anisotropic porous ductile sheet metals, Mechanics of Materials 26 (4) (1997) $213-226$.

[26] A. A. Benzerga, J. Besson, Plastic potentials for anisotropic porous solids, Eur. J. Mech. A. Solids 20 (2001) 397-434.

[27] S. M. Keralavarma, A. A. Benzerga, An approximate yield criterion for anisotropic porous media, C.R. Mec. 336 (9) (2008) 685-692.

[28] J. Leblond, G. Perrin, P. Suquet, Exact results and approximate models for porous viscoplastic solids, Int J Plasticity 10 (3) (1994) 213 - 235.

[29] H. Klöcker, V. Tvergaard, Growth and coalescence of non-spherical voids in metals deformed at elevated temperature, Int. J. Mech. Sci. 45 (8) (2003) 1283-1308. 
[30] F. Scheyvaerts, P. Onck, C. Tekog̃lu, T. Pardoen, The growth and coalescence of ellipsoidal voids in plane strain under combined shear and tension, J Mech Phys Solids 59 (2) (2011) 373 - 397.

[31] K. Nahshon, J. Hutchinson, Modification of the Gurson model for shear failure, Eur. J. Mech. A. Solids 27 (1) (2008) 1-17.

[32] M. Worswick, Z. Chen, A. Pilkey, D. Lloyd, S. Court, Damage characterization and damage percolation modelling in aluminum alloy sheet, Acta Mater 49 (14) (2001) 2791-2803.

[33] Z. L. Zhang, E. Niemi, A new failure criterion for the Gurson-Tvergaard dilational constitutive model, Int. J. Fract. 70 (4) (1995) 321-334.

[34] A. Benzerga, Micromechanics of coalescence in ductile fracture, J Mech Phys Solids 50 (6) (2002) 1331 -1362 .

[35] L. Lecarme, C. Tekog̃lu, T. Pardoen, Void growth and coalescence in ductile solids with stage iii and stage iv strain hardening, Int J Plasticity 27 (8) (2011) 1203 - 1223.

[36] C. Tekog̃lu, J.-B. Leblond, T. Pardoen, A criterion for the onset of void coalescence under combined tension and shear, J Mech Phys Solids 60 (7) (2012) 1363 - 1381.

[37] F. Scheyvaerts, T. Pardoen, P. Onck, A new model for void coalescence by internal necking, Int J Damage Mech.

[38] L. Morin, J.-B. Leblond, A. A. Benzerga, Coalescence of voids by internal necking: Theoretical estimates and numerical results, J Mech Phys Solids (0) (2014) -.

[39] L. Babout, E. Maire, R. Fougres, Damage initiation in model metallic materials: X-ray tomography and modelling, Acta Mater 52 (8) (2004) 2475 - 2487.

[40] C. Tekog̃lu, T. Pardoen, A micromechanics based damage model for composite materials, Int. J. Plast. 26 (4) (2010) $549-569$.

[41] G. Huber, Y. Bréchet, T. Pardoen, Predictive model for void nucleation and void growth controlled ductility in quasi-eutectic cast aluminium alloys, Acta Mater. 53 (9) (2005) 2739-2749.

[42] D. Wilkinson, E. Maire, R. Fougeres, A model for damage in a clustered particulate composite, Mat Sci Eng A 262 (12) (1999) $264-270$.

[43] Z. Chen, C. Butcher, Application of the complete percolation model, in: Micromechanics Modelling of Ductile Fracture, Vol. 195 of Solid Mechanics and Its Applications, Springer Netherlands, 2013, pp. $275-290$.

[44] L. Devillers-Guerville, J. Besson, A. Pineau, Notch fracture toughness of a cast duplex stainless steel: modelling of experimental scatter and size effect, Nucl Eng Des 168 (1) (1997) 211-225. 
[45] S. Moorthy, S. Ghosh, A voronoi cell finite element model for particle cracking in elastic-plastic composite materials, Comput Method Appl M 151 (34) (1998) 377 - 400.

[46] C. Landron, O. Bouaziz, E. Maire, J. Adrien, Characterization and modeling of void nucleation by interface decohesion in dual phase steels, Scripta Mater 63 (10) (2010) 973 - 976.

[47] C. Landron, E. Maire, O. Bouaziz, J. Adrien, L. Lecarme, A. Bareggi, Validation of void growth models using x-ray microtomography characterization of damage in dual phase steels, Acta Mater 59 (20) (2011) $7564-7573$.

[48] C. Landron, O. Bouaziz, E. Maire, J. Adrien, Experimental investigation of void coalescence in a dual phase steel using x-ray tomography, Acta Mater 61 (18) (2013) 6821 - 6829.

[49] A. Simar, K. Nielsen, B. de Meester, V. Tvergaard, T. Pardoen, Micro-mechanical modelling of ductile failure in 6005a aluminium using a physics based strain hardening law including stage $\{I V\}$, Eng Fract Mech 77 (13) (2010) $2491-2503$.

[50] M. Stampanoni, F. Marone, P. Modregger, B. Pinzer, T. Thuring, J. Vila Comamala, C. David, R. Mokso, Tomographic hard xray phase contrast micro and nano imaging at tomcat, AIP Conference Proceedings 1266 (1) (2010) 13-17.

[51] J.-Y. Buffière, E. Maire, P. Cloetens, G. Lormand, R. Fougères, Characterization of internal damage in a MMCp using X-ray synchrotron phase contrast microtomography, Acta Mater 47 (5) (1999) 1613 1625 .

[52] E. Maire, O. Bouaziz, M. Di Michiel, C. Verdu, Initiation and growth of damage in a dual-phase steel observed by X-ray microtomography, Acta Mater 56 (18) (2008) 4954-4964.

[53] L. Lecarme, E. Maire, A. K. K.C., C. D. Vleeschouwer, L. Jacques, A. Simar, T. Pardoen, Heterogenous void growth revealed by in situ 3-d x-ray microtomography using automatic cavity tracking, Acta Mater $63(0)(2014) 130-139$.

[54] M. Berveiller, A. Zaoui, An extension of the self-consistent scheme to plastically-flowing polycrystals, J Mech Phys Solids 26 (56) (1978) 325 - 344.

[55] R. Hill, A self-consistent mechanics of composite materials, J Mech Phys Solids 13 (4) (1965) 213 - 222.

[56] D. Lassance, F. Scheyvaerts, T. Pardoen, Growth and coalescence of penny-shaped voids in metallic alloys, Eng. Fract. Mech. 73 (8) (2006) 1009-1034.

[57] Y. Huang, Accurate dilatation rates for spherical voids in triaxial stress fields, J. Appl. Mech. 58 (4) (1991) 1084-1086. doi:10.1115/1.2897686. 
[58] M. Worswick, R. Pick, Void growth and constitutive softening in a periodically voided solid, J Mech Phys Solids 38 (5) (1990) $601-625$.

[59] V. Tvergaard, Void shape effects and voids starting from cracked inclusion, Int J Solids Struct 48 (78) (2011) $1101-1108$.

[60] C. Butcher, A multi-scale damage percolation model of ductile fracture, Ph.D. thesis, University of New Brunswick (2011).

[61] B. Marini, F. Mudry, A. Pineau, Ductile rupture of a508 steel under nonradial loading, Eng Fract Mech $22(3)(1985) 375-386$.

[62] T. Pardoen, F. Delannay, Assessment of void growth models from porosity measurements in cold-drawn copper bars, Metall Mater Trans A 29 (1998) 1895-1909.

[63] ABAQUS Theory Manual Version 6.8, Hibbitt, Karlsson and Sorenson Inc., 2002.

[64] MATLAB Version 8.1.0.604 (R2013a), The MathWorks Inc., 2013.

[65] H. Toda, H. Oogo, K. Horikawa, K. Uesugi, A. Takeuchi, Y. Suzuki, M. Nakazawa, Y. Aoki, M. Kobayashi, The true origin of ductile fracture in aluminum alloys, Metall Mater Trans A 45 (2) (2014) 765-776. 


\section{List of Figures}

1 Variation of the different parameters extracted from the uniaxial tensile tests on the three alloys as a function of the yield stress corresponding to the different heat treatments. (a) True fracture strain of three $\mathrm{Al}$ alloys; $(b)$ true strain at the onset of necking; $(c)$ dislocation storage rate $\theta_{0}$ of the Voce law; $(d)$ dynamic recovery parameter $\beta \ldots \ldots \ldots \ldots \ldots$

2 Schematic representation of the method used to analyse the probability of fracture of intermetallic iron-rich particles at various distances from the fracture surface of broken tensile samples polished down to mid-thickness; for each particle, record position, dimensions and broken or not broken (here a 6056 alloy specimen), micrograph obtained by FEG-SEM. The color map shows the finite element simulation predictions of the tensile test. . . . . . . . .

3 (a) Void nucleation on particle. (b) Result of the growth model at different $\varepsilon_{\text {Growth }}=\varepsilon_{\text {Loc }}-$ $\varepsilon_{\text {Nucleation. }}$ (c) Definition of the effective parameters used to apply the coalescence criterion. $(d)$ Equivalent geometry. (e) Result of the merging process : minimum ellipsoid that envelops both coalescing voids. $(f)$ Exemple of a whole RVE at a local strain $\varepsilon=0.25$. $(a-f)$ The particle is in blue, the voids in red and the coalesced voids in grey. . . . . . . . . . . .

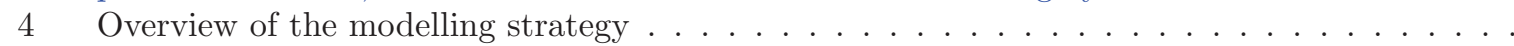

5 Characterization of intermetallic particles sizes and initial porosity by X-ray microtomography and SEM. (a) 3D microtomography perspective of particles (blue) and pores (red) distribution in all three alloys. Distribution of equivalent diameter for the intermetallic particles; (b) based on the 3D X-ray microtomography images (c) based on the SEM micrographs. . . . . . . . .

$6 \quad$ Yield stress $\sigma_{0}$ corresponding to the various heat treatments performed on the three alloys. .

7 Comparison between the experimental and modelled (best identification) fraction of broken particles as a function of the particles equivalent diameter in the three alloys for all heat treatment conditions. . . . . . . . . . . . . . . . . . . .

8 (a) Evolution of the rates of change of the equivalent radius of every void $\frac{R_{e q}}{R_{e q}, 0}$ as a function of strain after nucleation; (b) Evolution of the mean rate of change $\frac{R_{e q}}{R_{e q, 0}}$ of all voids; (c) Evolution of the mean void aspect ratio $W_{v o i d} \ldots \ldots \ldots \ldots \ldots \ldots$

9 (a) Comparaison between the variations of the void volume fraction $(f)$ measured during insitu microtomography and the void volume fraction predicted by the model as a function of the local strain in the necking zone; $(b)$ Zoom in figure $(\mathrm{a}) . \ldots \ldots \ldots$. . . . . . . . .

10 Results of the model applied to the Al 6056 alloy for three heat treatments (namely T6, T4 and overaged with $\sigma_{0} \simeq 60 \mathrm{MPa}$ ). Comparaison between : $(a)$ the variations of the void volume fractions; $(b)$ fraction of broken particles extracted from the model; $(c)$ number of coalescence events; $(d)$ total number of voids. All the data are extracted from the model and their evolution are presented as a function of the local strain in the necking zone. The point on each curve corresponds to the predicted fracture strain. . . . . . . . . . . . . . . .

11 Comparaison between the experimental fracture strain and the fracture strain of the model as a function of yield stress. The plain line corresponds to the linear regression of experimental values. The dotted line corresponds to the linear regression of the values from the model. . .

12 Sensitivity analysis on different contributions of the cellular automaton model. The "full model" corresponds to the predictions of the model derived in the present paper and used in Fig. 10 and Fig. 11 for comparison to experimental data. The "modified models" are degraded versions of the model. . . . . . . . . . . . . . . . . . . . . .

13 Definition of the effective void dimensions used in the growth model. . . . . . . . . . . . . 


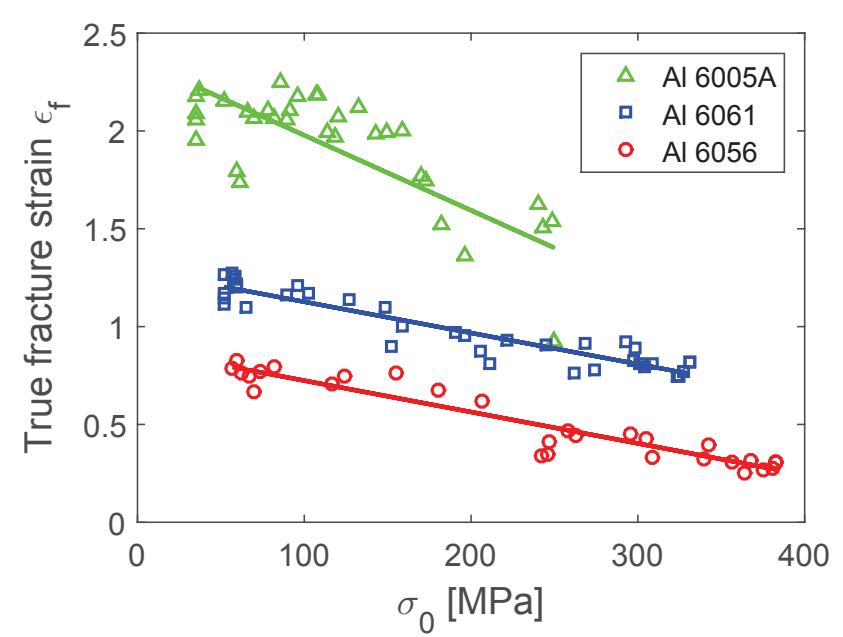

(a)

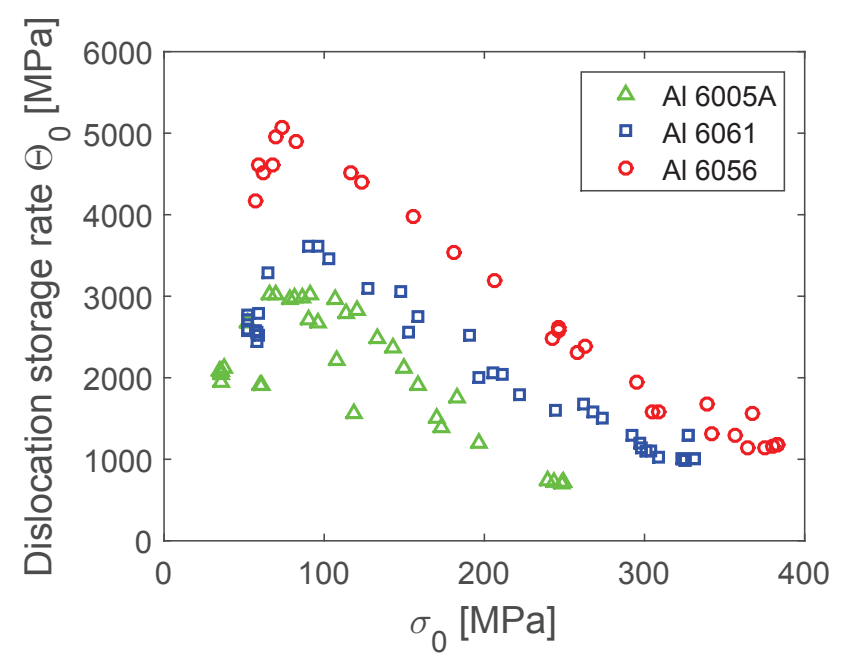

(c)

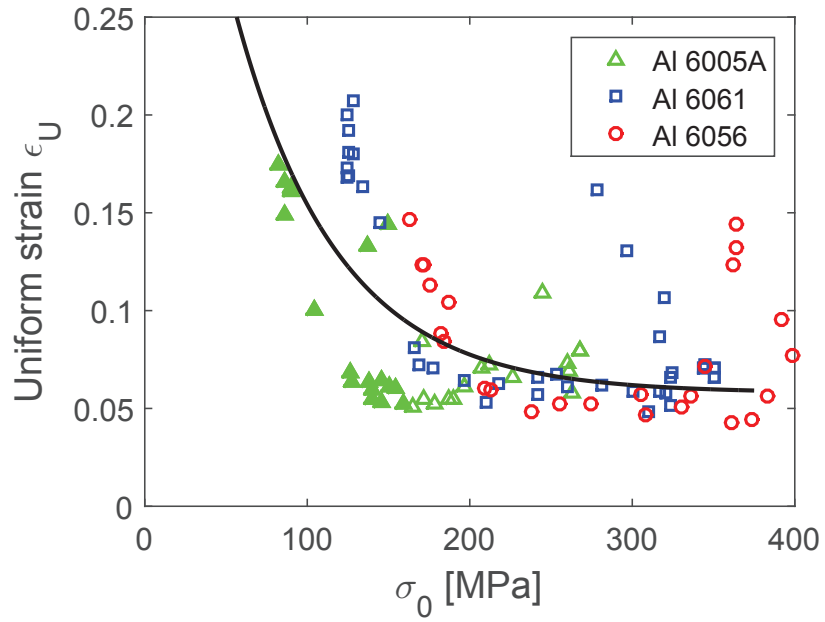

(b)

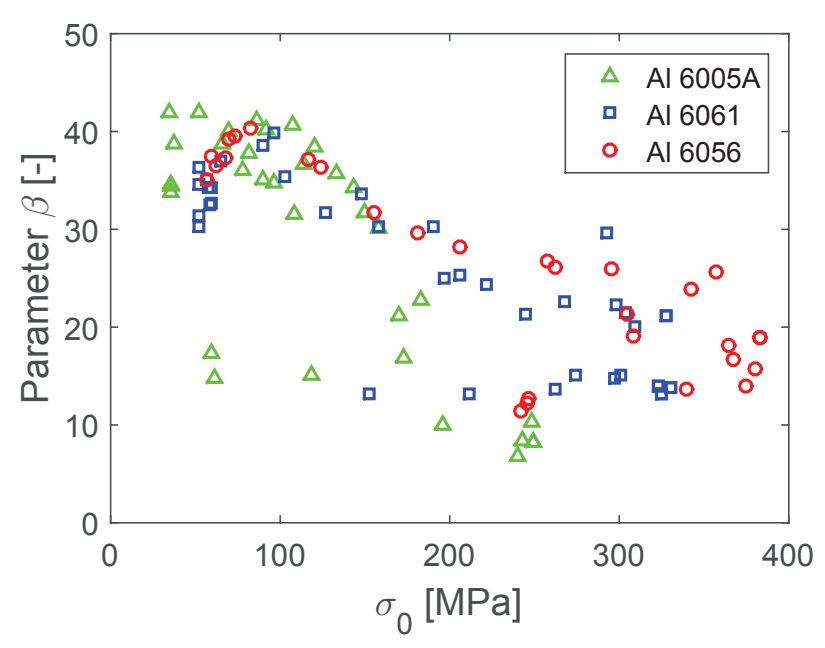

(d)

Figure 1: Variation of the different parameters extracted from the uniaxial tensile tests on the three alloys as a function of the yield stress corresponding to the different heat treatments. ( $a$ ) True fracture strain of three Al alloys; $(b)$ true strain at the onset of necking; $(c)$ dislocation storage rate $\theta_{0}$ of the Voce law; $(d)$ dynamic recovery parameter $\beta$. 


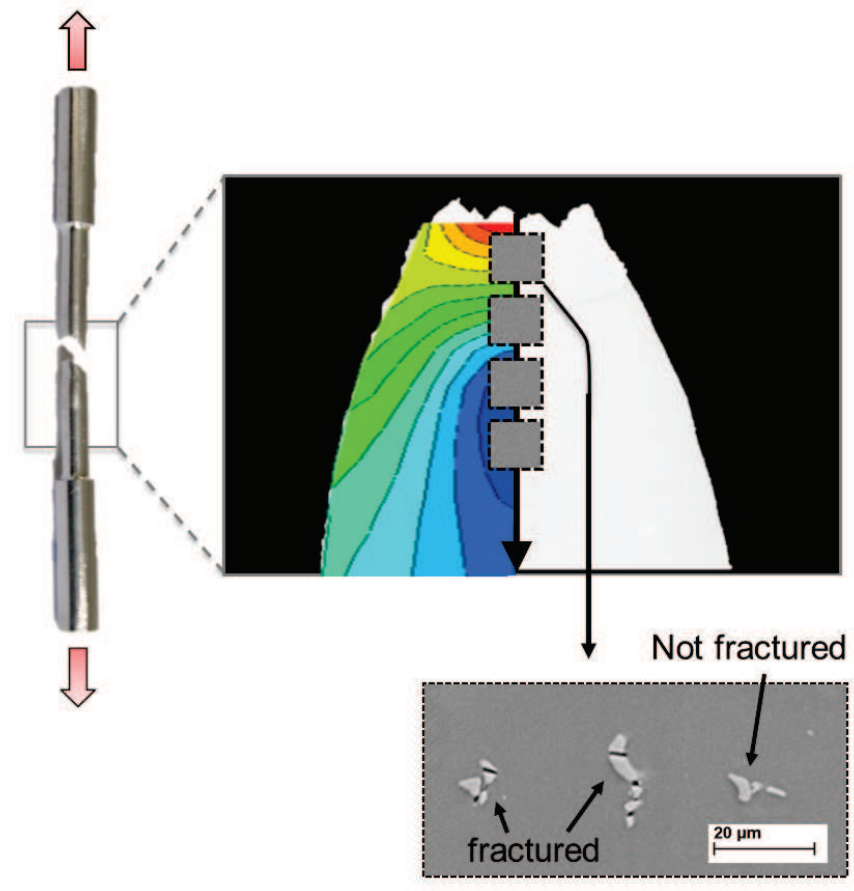

Figure 2: Schematic representation of the method used to analyse the probability of fracture of intermetallic iron-rich particles at various distances from the fracture surface of broken tensile samples polished down to mid-thickness; for each particle, record position, dimensions and broken or not broken (here a 6056 alloy specimen), micrograph obtained by FEG-SEM. The color map shows the finite element simulation predictions of the tensile test. 


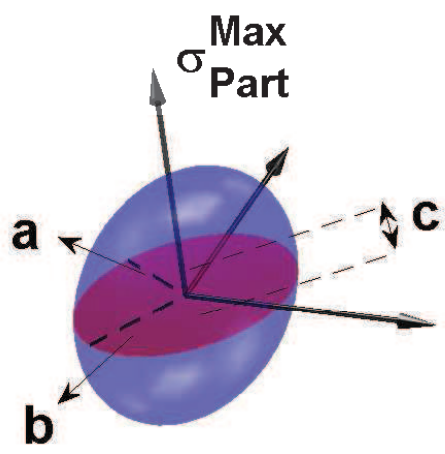

(a)

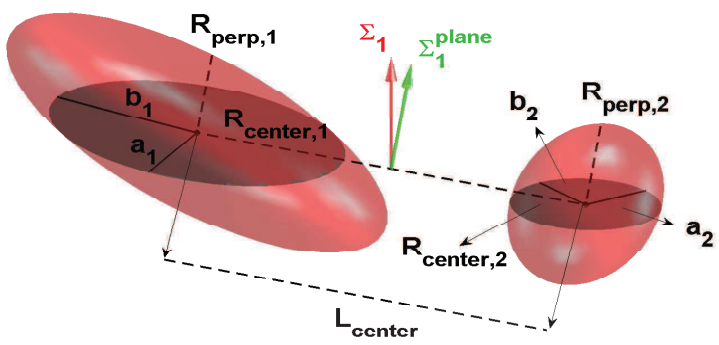

(c)

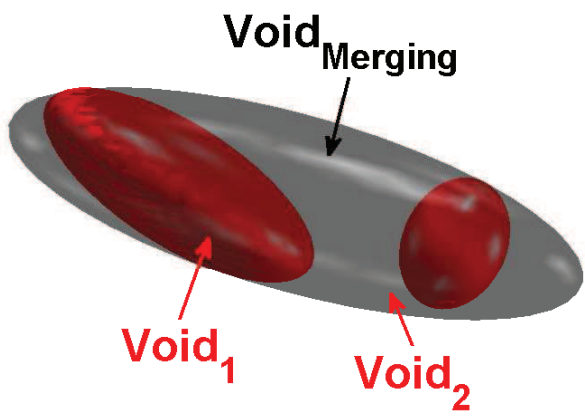

(e)
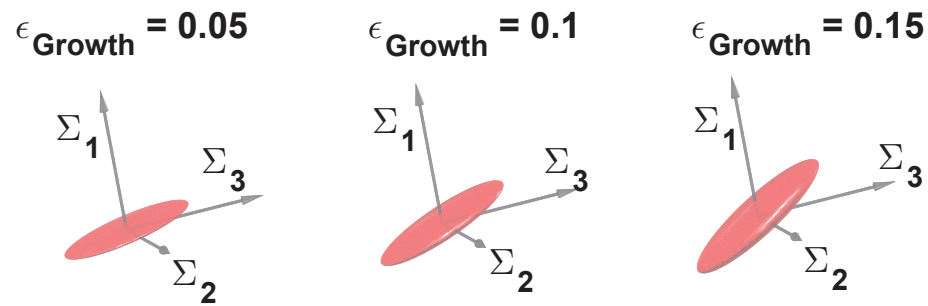

(b)

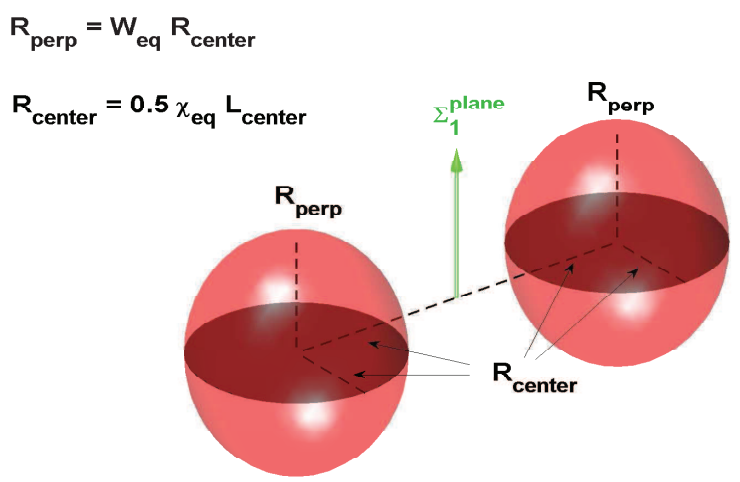

(d)

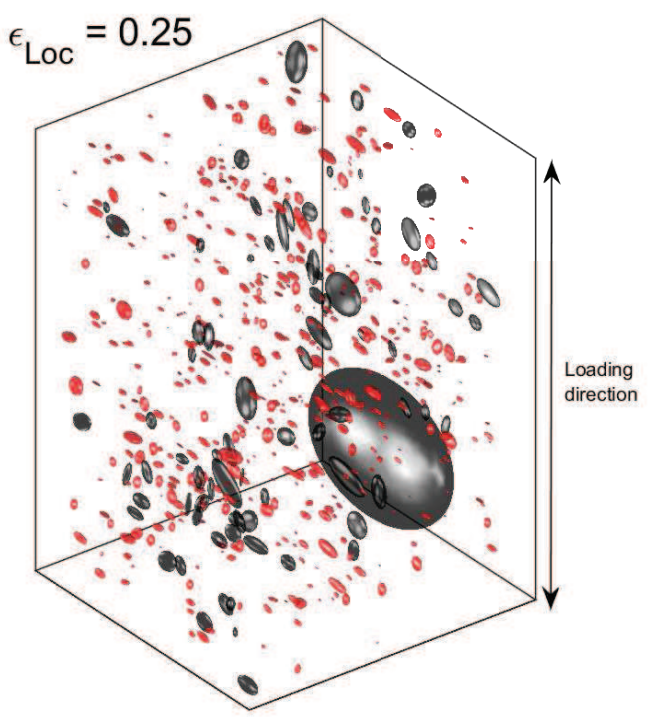

(f)

Figure 3: (a) Void nucleation on particle. (b) Result of the growth model at different $\varepsilon_{\text {Growth }}=\varepsilon_{\text {Loc }}-\varepsilon_{N u c l e a t i o n}$. (c) Definition of the effective parameters used to apply the coalescence criterion. $(d)$ Equivalent geometry. $(e)$ Result of the merging process : minimum ellipsoid that envelops both coalescing voids. $(f)$ Exemple of a whole RVE at a local strain $\varepsilon=0.25$. $(a-f)$ The particle is in blue, the voids in red and the coalesced voids in grey. 


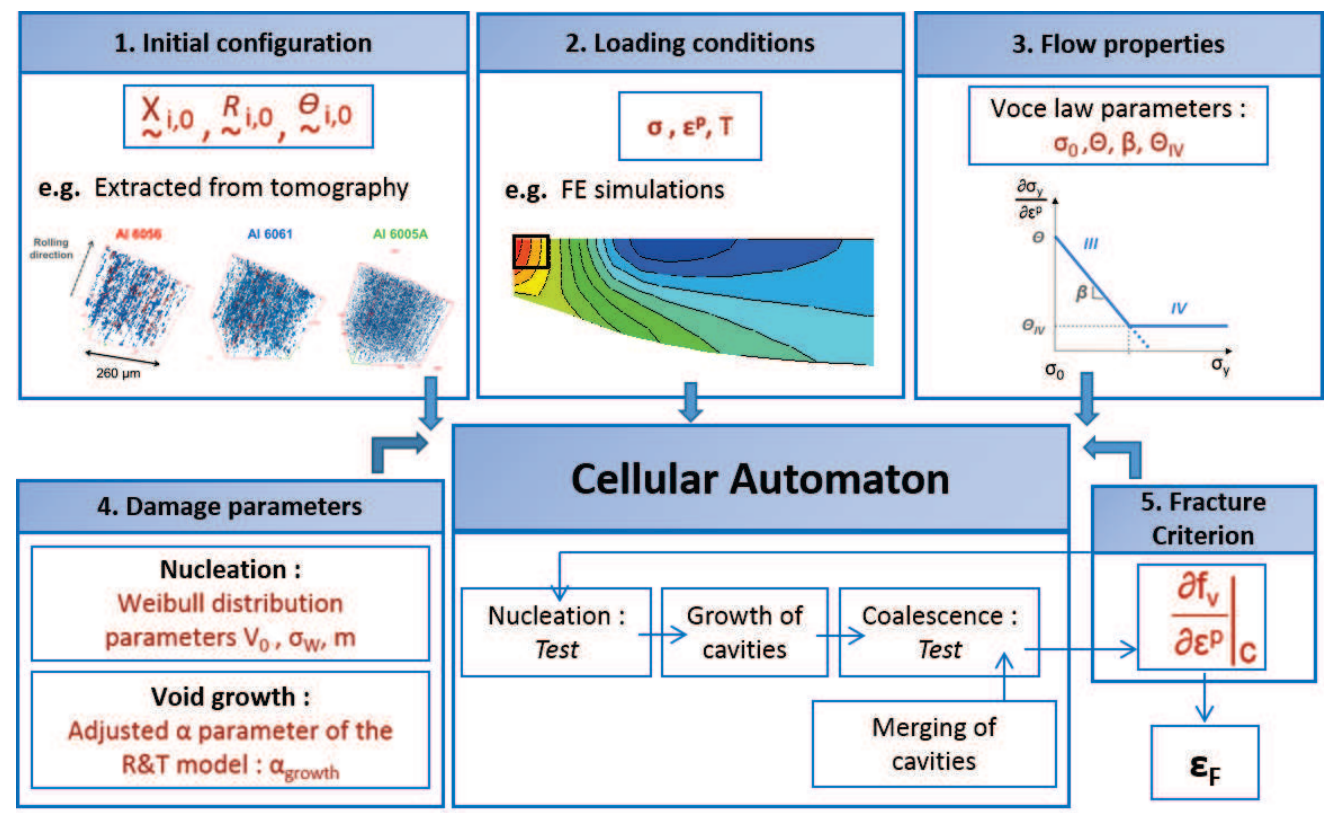

Figure 4: Overview of the modelling strategy 

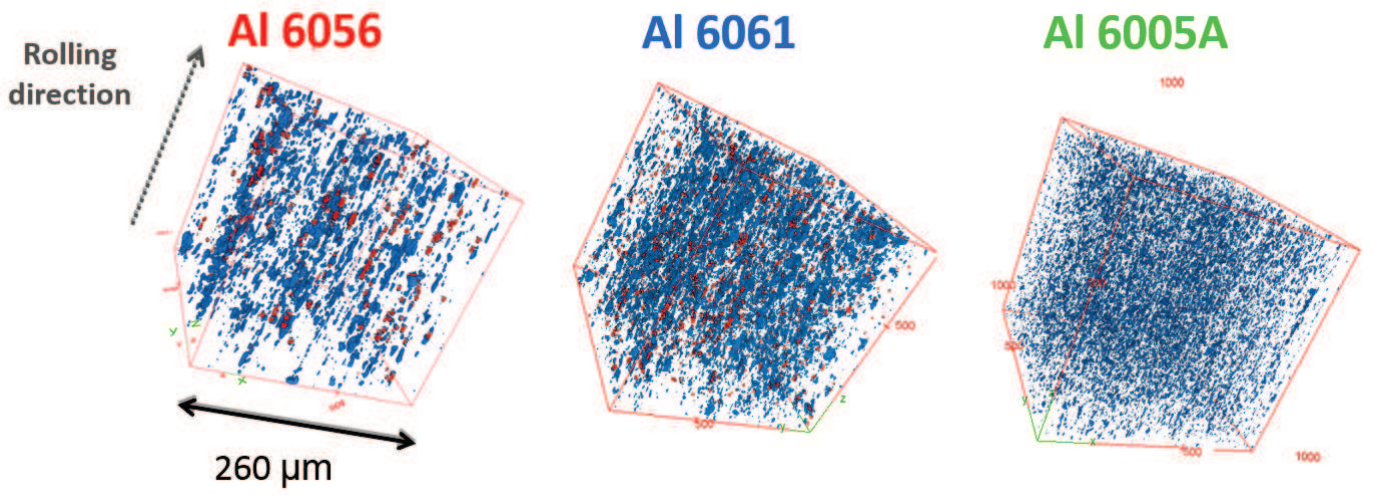

(a)

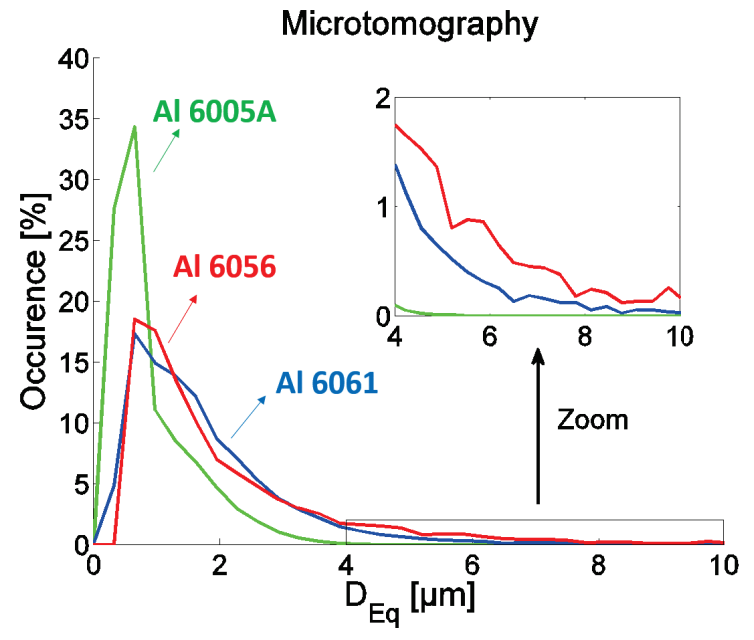

(b)

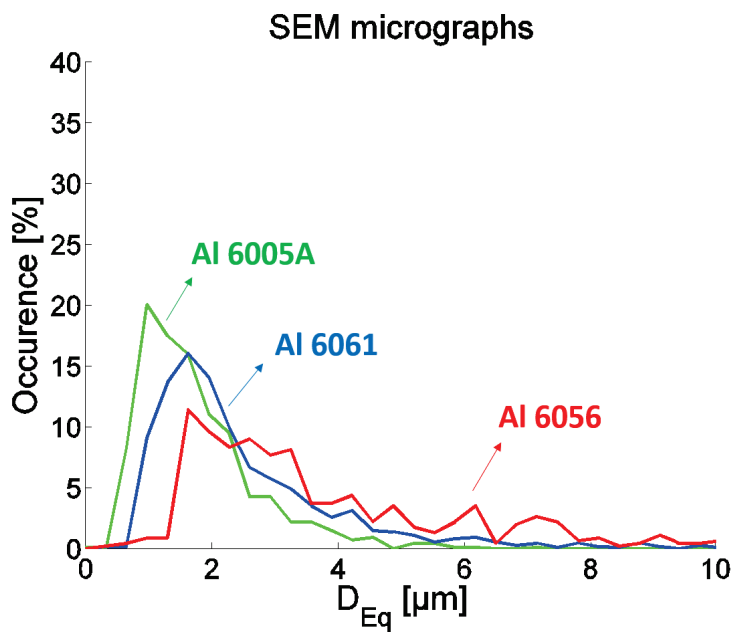

(c)

Figure 5: Characterization of intermetallic particles sizes and initial porosity by X-ray microtomography and SEM. (a) 3D microtomography perspective of particles (blue) and pores (red) distribution in all three alloys. Distribution of equivalent diameter for the intermetallic particles; (b) based on the 3D X-ray microtomography images (c) based on the SEM micrographs. 


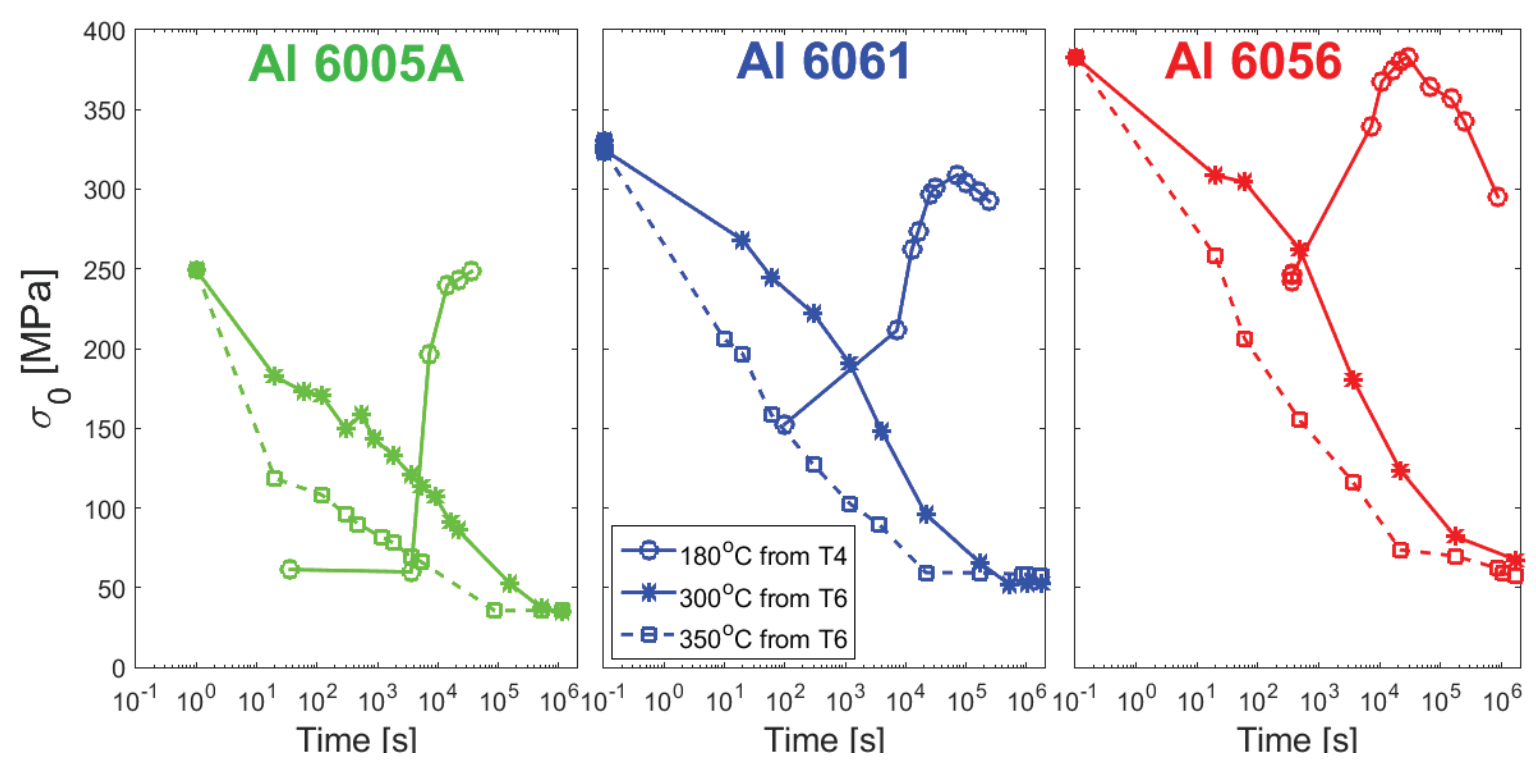

Figure 6: Yield stress $\sigma_{0}$ corresponding to the various heat treatments performed on the three alloys. 


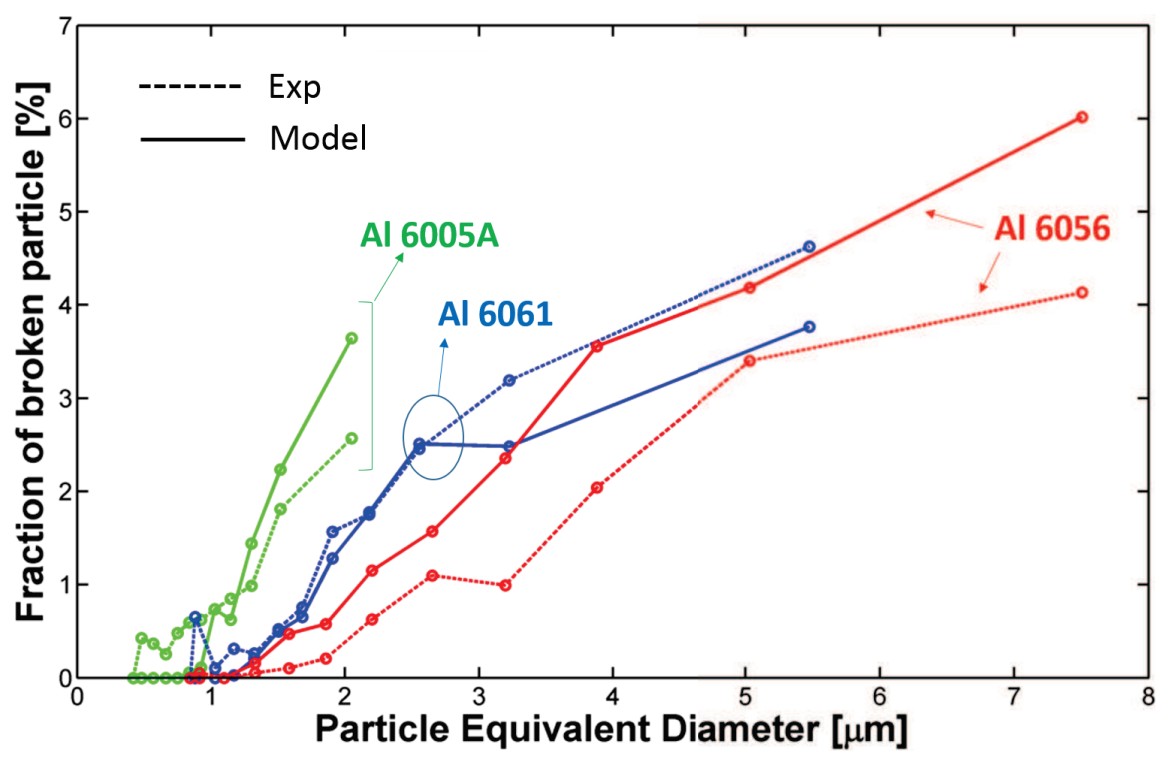

(a)

Figure 7: Comparison between the experimental and modelled (best identification) fraction of broken particles as a function of the particles equivalent diameter in the three alloys for all heat treatment conditions. 


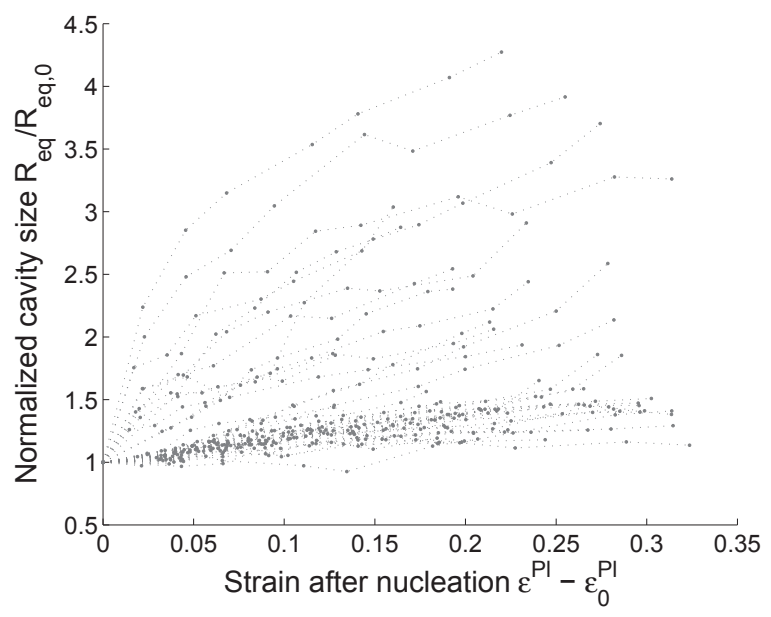

(a)

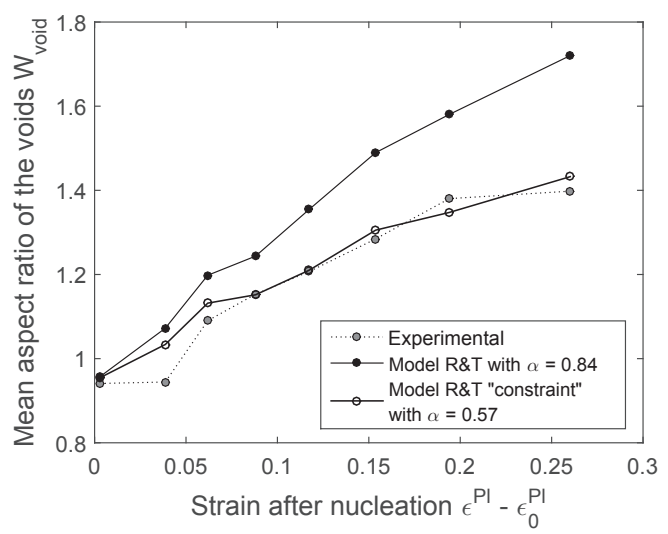

(b)

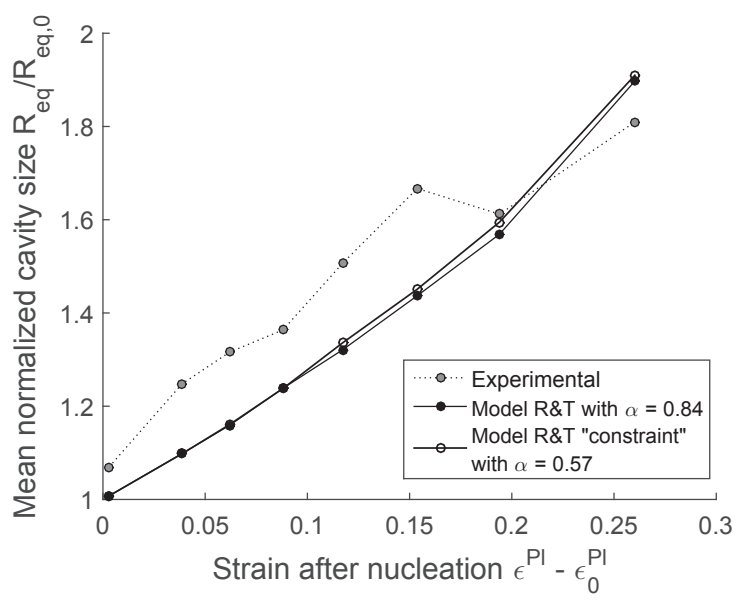

(c)

Figure 8: (a) Evolution of the rates of change of the equivalent radius of every void $\frac{R_{e q}}{R_{e q, 0}}$ as a function of strain after nucleation; (b) Evolution of the mean rate of change $\frac{R_{e q}}{R_{e q, 0}}$ of all voids; (c) Evolution of the mean void aspect ratio $W_{v o i d}$. 


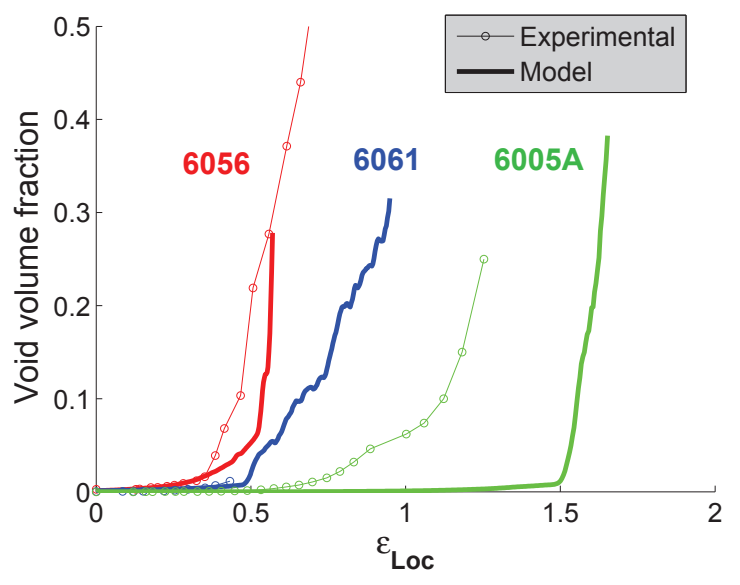

(a)

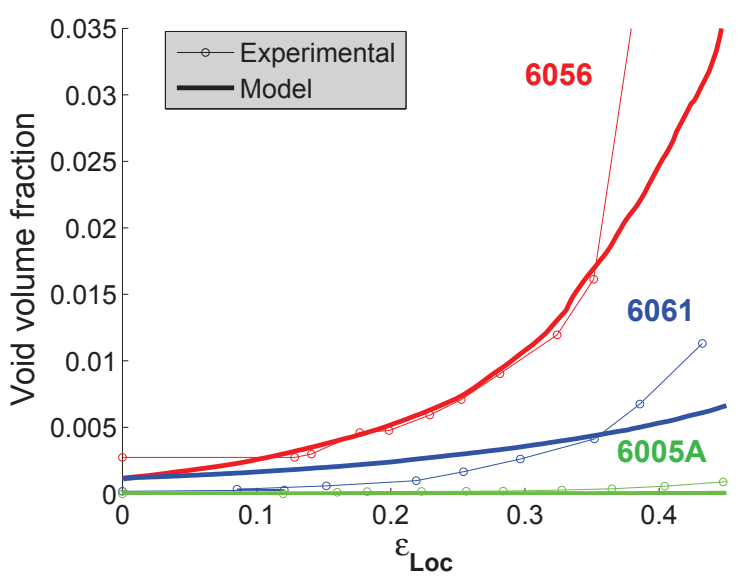

(b)

Figure 9: (a) Comparaison between the variations of the void volume fraction $(f)$ measured during in-situ microtomography and the void volume fraction predicted by the model as a function of the local strain in the necking zone; $(b)$ Zoom in figure (a). 

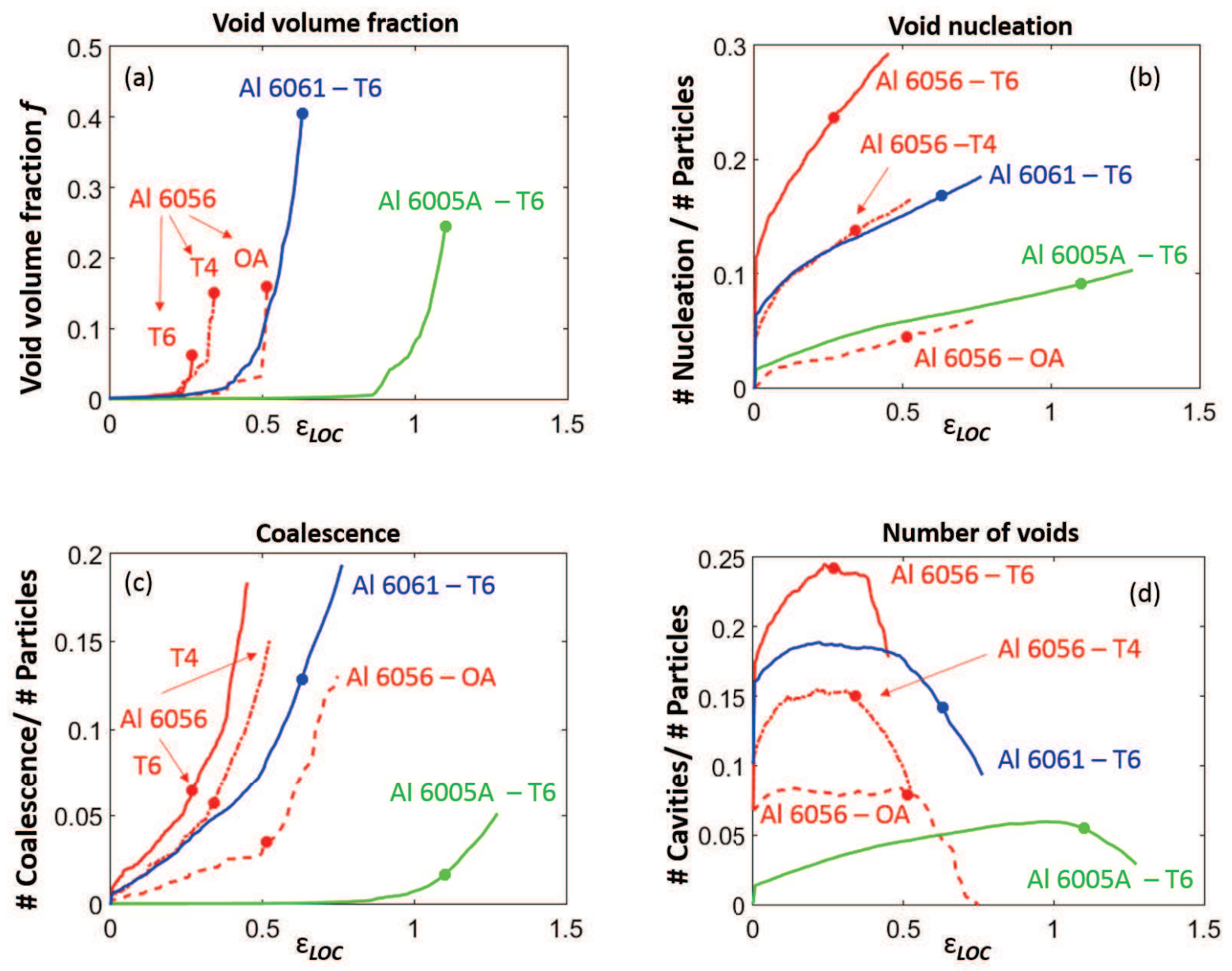

Figure 10: Results of the model applied to the Al 6056 alloy for three heat treatments (namely T6, T4 and overaged with $\sigma_{0} \simeq$ $60 \mathrm{MPa})$. Comparaison between : $(a)$ the variations of the void volume fractions; $(b)$ fraction of broken particles extracted from the model; $(c)$ number of coalescence events; $(d)$ total number of voids. All the data are extracted from the model and their evolution are presented as a function of the local strain in the necking zone. The point on each curve corresponds to the predicted fracture strain. 


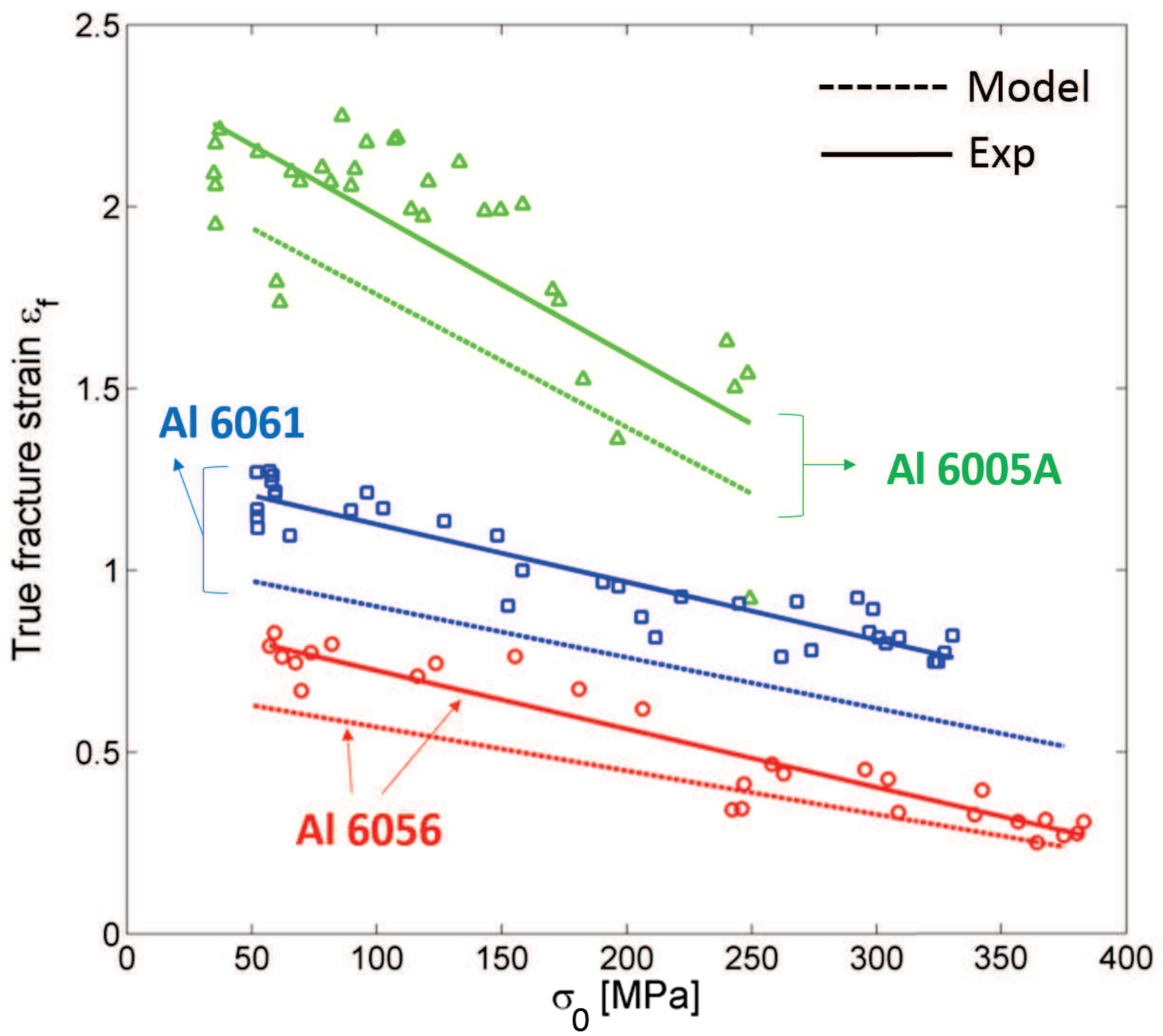

Figure 11: Comparaison between the experimental fracture strain and the fracture strain of the model as a function of yield stress. The plain line corresponds to the linear regression of experimental values. The dotted line corresponds to the linear regression of the values from the model. 


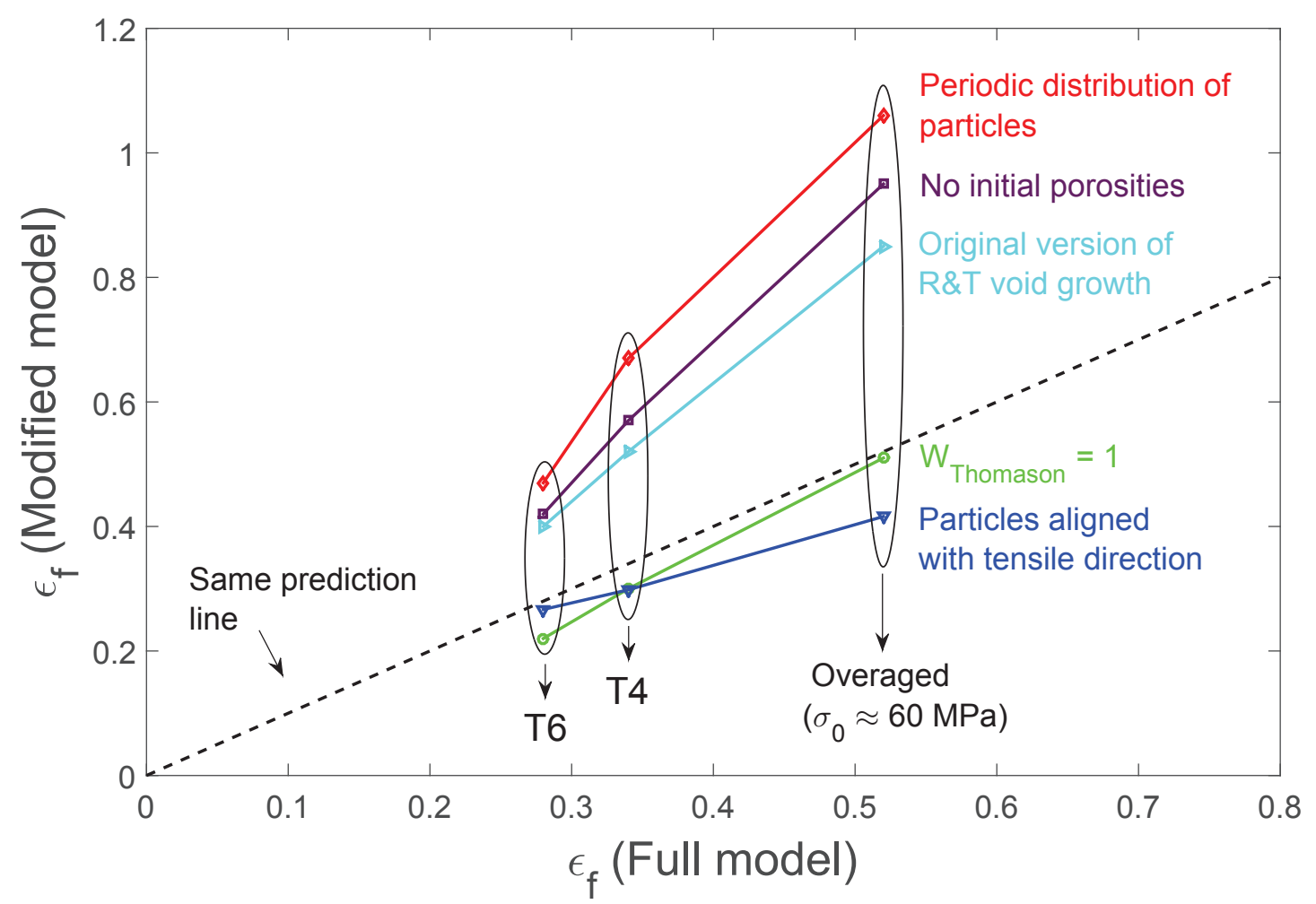

Figure 12: Sensitivity analysis on different contributions of the cellular automaton model. The "full model" corresponds to the predictions of the model derived in the present paper and used in Fig. 10 and Fig. 11 for comparison to experimental data. The "modified models" are degraded versions of the model. 


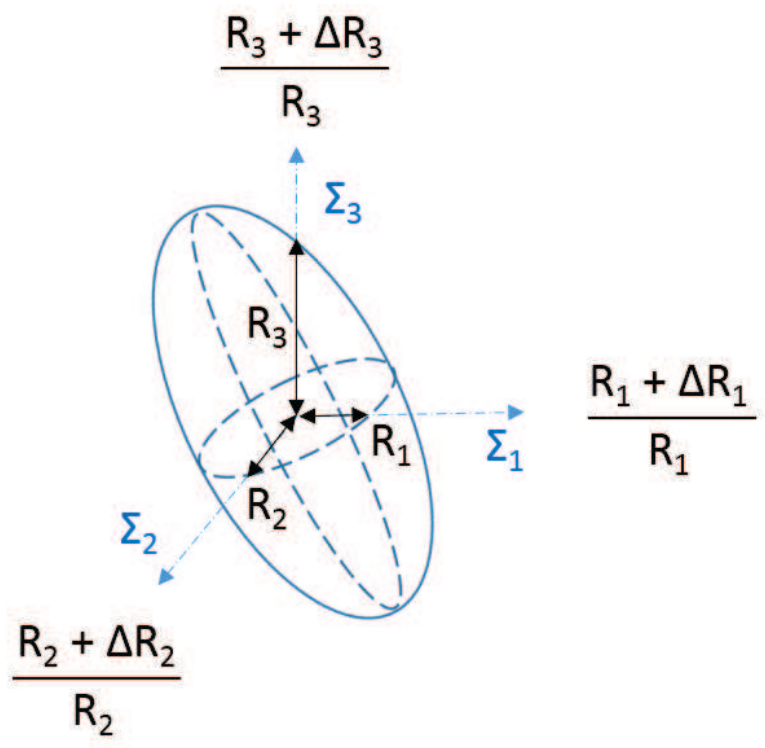

Figure 13: Definition of the effective void dimensions used in the growth model. 


\section{List of Tables}

1 Chemical composition measured by ICP-OES of the 6005A, 6061 and $6056 \mathrm{Al}$ alloys [wt.\%] $\mathrm{Al}$ content is the balance. . . . . . . . . . . . . . . . . . . . . . . . .

2 Mean volume fraction, shape factor, diameter (based on the surface area) of the intermetallic particles in the three aluminium alloys; results based on FEG-SEM image analysis; observations performed at mid-thickness viewed from the top of the plates. . . . . . . . . . . . . . . . . . . 40

3 Mean volume fraction and equivalent diameter (based on X-ray microtomography images) of the initial porosities. . . . . . . . . . . . . . . . . . . . . . 


\begin{tabular}{|c|c|c|c|c|c|c|c|c|c|}
\hline Alloy & $\boldsymbol{M g}$ & $\boldsymbol{S i}$ & $\boldsymbol{C u}$ & $\boldsymbol{F e}$ & $\boldsymbol{M n}$ & $\boldsymbol{C r}$ & $\boldsymbol{Z n}$ & $\boldsymbol{T i}$ & $\boldsymbol{A l}$ \\
\hline $\boldsymbol{A} \boldsymbol{l} \mathbf{6 0 0 5} \boldsymbol{A}$ & 0.47 & 0.60 & 0.09 & 0.23 & 0.11 & $<0.01$ & 0.07 & 0.02 & 98.73 \\
\hline $\boldsymbol{A l} \mathbf{6 0 6 1}$ & 0.88 & 0.58 & 0.23 & 0.39 & 0.05 & 0.18 & 0.03 & 0.02 & 98.44 \\
\hline $\boldsymbol{A l} \mathbf{6 0 5 6}$ & 0.75 & 0.95 & 0.64 & 0.11 & 0.61 & $<0.01$ & 0.18 & 0.01 & 97.5 \\
\hline
\end{tabular}

Table 1: Chemical composition measured by ICP-OES of the 6005A, 6061 and $6056 \mathrm{Al}$ alloys [wt.\%] $\mathrm{Al}$ content is the balance. 


\begin{tabular}{|c|c|c|c|c|}
\cline { 3 - 4 } \multicolumn{2}{c}{} & \multicolumn{3}{c|}{ Alloy } \\
\hline Technique & Parameter & Al $\mathbf{6 0 0 5} \boldsymbol{A}$ & Al $\mathbf{6 0 6 1}$ & Al $\mathbf{6 0 5 6}$ \\
\hline SEM & Surface fraction & $1.2 \%$ & $1.2 \%$ & $1.0 \%$ \\
\hline Microtomography & Volume fraction & $0.6 \%$ & $1.1 \%$ & $0.85 \%$ \\
\hline SEM & \multirow{2}{*}{ Shape factor } & $1.7 \pm 0.7$ & $1.6 \pm 0.6$ & $1.7 \pm 0.9$ \\
\cline { 1 - 4 } Microtomography & \multirow{2}{*}{ Equivalent diameter } & $1.3 \pm 0.7 \mu \mathrm{m}$ & $2.1 \pm 1.3 \mu \mathrm{m}$ & $3.1 \pm 2.1 \mu \mathrm{m}$ \\
\cline { 3 - 5 } & & $0.9 \pm 0.7 \mu \mathrm{m}$ & $1.8 \pm 1.3 \mu \mathrm{m}$ & $2.1 \pm 1.8 \mu \mathrm{m}$ \\
\hline Microtomography & & &
\end{tabular}

Table 2: Mean volume fraction, shape factor, diameter (based on the surface area) of the intermetallic particles in the three aluminium alloys; results based on FEG-SEM image analysis; observations performed at mid-thickness viewed from the top of the plates. 


\begin{tabular}{|c|c|c|}
\cline { 2 - 3 } \multicolumn{1}{c|}{} & \multicolumn{2}{c|}{ Alloy } \\
\hline Parameter & Al $\mathbf{6 0 6 1}$ & Al $\mathbf{6 0 5 6}$ \\
\hline Volume fraction & $0.11 \%$ & $0.12 \%$ \\
\hline Equivalent diameter & $2.4 \pm 1.1$ & $3.7 \pm 2.2$ \\
\hline Shape factor & 1.7 & 1.85 \\
\hline
\end{tabular}

Table 3: Mean volume fraction and equivalent diameter (based on X-ray microtomography images) of the initial porosities. 